\title{
Comparative analysis of interpolation methods in the middle Ebro Valley (Spain): application to annual precipitation and temperature
}

\author{
Sergio M. Vicente-Serrano*, M. Angel Saz-Sánchez, José M. Cuadrat \\ Department of Geography, University of Zaragoza, Campus San Francisco, 50009 Zaragoza, Spain
}

\begin{abstract}
This paper analyzes the validity of various precipitation and temperature maps obtained by means of diverse interpolation methods. The study was carried out in an area where geographic differences and spatial climatic diversity are significant (the middle Ebro Valley in the northeast of Spain). Two variables, annual precipitation and temperature, and several interpolation methods were used in the climate mapping: global interpolators (trend surfaces and regression models), local interpolators (Thiessen polygons, inverse distance weighting, splines), geostatistical methods (simple kriging, ordinary kriging, block kriging, directional kriging, universal kriging and co-kriging) and mixed methods (combined global, local and geostatistical methods). The validity of the maps was checked through independent test weather stations (30\% of the original stations). Different statistical accuracy measurements determined the quality of the models. The results show that some interpolation methods are very similar. Nevertheless, in the case of precipitation maps, we obtained the best results using geostatistical methods and a regression model formed by 4 geographic and topographic variables. The best results for temperature mapping were obtained using the regression-based method. The accuracy measurements obtained by the different interpolation methods change significantly depending on the climatic variable mapped. The validity of interpolation methods in the creation of climatic maps, useful for agricultural and hydrologic management, is discussed.
\end{abstract}

KEY WORDS: Interpolation · Geostatistical techniques · Regression · Temperature $\cdot$ Precipitation · Ebro Valley · Spain

Resale or republication not permitted without written consent of the publisher

\section{INTRODUCTION}

As many biotic and abiotic processes are determined by the climatic characteristics of the environment, scientific disciplines such as agronomy, climatology, biology and ecology, among others, use climatic data for scientific and technical purposes. Climatic data is problematic due to the quality of the information (Peterson et al. 1998) and the spatial and temporal coverage of the data. This problem is assuaged by quality control and homogenization methods (Rhoades \& Salinger 1993, Easterling \& Peterson 1995, Alexandersson \& Moberg 1997), mainly used in studies of climatic trends and environmental change. The spatial availability of climatic data is more problematic, because the information is recorded at permanent but very disperse weather stations. On many occasions, climatic data are not available where they are most needed.

To solve this problem, various statistical methods have been developed to predict climatic values in areas without weather stations. Scientific literature focuses more on the climatic variables in mountainous areas (Daly et al. 1994, Prudhomme \& Reed 1998, Goovaerts 1999), because topographic complexity generates a high diversity of micro-environments where climatic values are very difficult to predict (Daly et al. 2002). There are fewer difficulties in flatter areas. Nevertheless, many regions of gently-rolling-to-hilly terrain have very complex climatic patterns, due to the 
presence of surrounding mountain ranges, seasonal variations of air flows, and the frequent accumulation of cold air in the bottom valleys, which produce thermal inversions and fog. This climatic complexity causes great variation between neighboring locations and makes it difficult to predict climatic values where weather stations are not available. Despite these problems, prediction of climatic values on these hilly areas is relevant in both scientific and applied terms, because most agricultural, economic and recreational human activities are concentrated there.

Various statistical methods have been developed to predict the spatial distribution of climatic variables. These methods differ in their concept and mathematical formulation (Borrough \& McDonnell 1998). Global methods use external information (e.g. topographic and geographic data) to produce climatic maps by means of empirical simple- or multiple-regression models (e.g. Edwards 1972, Hargy 1997, Agnew \& Palutikof 2000, Ninyerola et al. 2000, Brown \& Comrie 2002). Konrad (1996) generated diverse models with topographic factors as predictor variables in the modeling of precipitation events of different intensity. Salas \& Chuvieco (1993) employed regression models for the interpolation of temperature and precipitation when producing a fire risk model. Goodale et al. (1998) interpolated temperature and precipitation in Ireland by means of polynomial regression, using latitude, longitude and altitude as predictors. Recently, Earth observation satellites have provided independent variables (e.g. surface temperature and NDVI [normalized difference vegetation index]), which have been used in regression models to reflect local climatic differences (Maseli et al. 1996, 1998, Vogt et al. 1997).

Other methods such as local interpolations only use the climatic data from weather stations. Climatic prediction at a given point is taken from data at the nearest weather stations. Using this data, a mathematical function is formulated, which is then used to predict the climatic value at that point. The process is spatially continuous, and finishes when the climatic data are predicted at all the points. Local interpolators, such as Thiessen polygons, inverse distance weighting or thinplate splines, have also been frequently used in climatic prediction and mapping (Thiessen 1911, Willmott et al. 1985, Hutchinson 1995, Willmott \& Robeson 1995, Blenow \& Persson 1998, New et al. 2000).

Nowadays, with regression models, the most widely used techniques in climate mapping are geostatistics (Cressie 1990, Atkinson 1997, Goovaerts 1997), which analyze the spatial correlation between the data recorded at several weather stations. This analysis gives unbiased predictions with minimum spatial variance (Curran \& Atkinson 1998). The methods assure optimal predictions according to the spatial variation of the data
(Borrough \& McDonnell 1998). Many different geostatistics have been developed recently. Some only use the climatic data recorded at the weather stations (e.g. simple kriging, ordinary kriging, block kriging), while others use topographic or geographic information (e.g. cokriging or universal kriging). The greater the number of variables, the more complex the methods. Several papers use geostatistics to interpolate climatic data (e.g. Dingman et al. 1988, Karnieli 1990, Bigg 1991, Phillips et al. 1992, Bacchi \& Kottegoda 1995), with varied results. Hevesi et al. (1992) obtained the best results with cokriging, which has less spatial variance than kriging. Similar results were obtained by Martínez-Cob (1996), who interpolated precipitation and evapotranspiration in a complex topographic area. However, Goovaerts (2000) found no significant differences between the most complex geostatistics and the simplest kriging methods, and Pardo-Igúzquiza (1998), in a comparison of geostatistics for the prediction of precipitation in a mountainous terrain, obtained the best results by means of universal kriging with external drift.

Other methods combine global, local and geostatistical techniques (Prudhomme \& Reed 1999, Ninyerola et al. 2000, Brown \& Comrie 2002). These methods examine the physical relationships between climatic data and geographic and topographic variables, and the spatial correlation between the information recorded at the weather stations.

This paper is a comparative study of these interpolation methods, based on annual temperature and precipitation. The middle Ebro Valley (NE Spain) was selected for the analysis. Here, annual climatic data is very pertinent to hydrologic and agricultural management. In the middle Ebro Valley, rather than monthly or seasonal records, it is annual precipitation that conditions the crop yields of non-irrigated lands (McAneney \& Arrúe 1993, Austin et al. 1998). Though the creation of annual climatic maps is the first step in hydrological management, in the middle Ebro Valley there are still no detailed automatic precipitation and temperature maps with continuous climatic data over space. Initially, the annual climatic maps need to be tested, the most appropriate methods studied, and then seasonal, monthly or daily temporal scales examined more closely.

\section{STUDY AREA}

The location of the study area is indicated in Fig. 1. The middle Ebro Valley is an excellent example of a gently-rolling-to-hilly topographic area with surrounding mountainous ranges and very complex (spatially and temporally) atmospheric patterns. It is an area dominated by horizontal structural platforms over ter- 
tiary deposits, with altitudes below $500 \mathrm{~m}$ (Pellicer \& Echeverría 1990). To the north, elevation can reach $2000 \mathrm{~m}$ on the southern slopes of the outposts of the Pyrenees. The Iberian mountain range is located to the south, where the highest peak is over $2300 \mathrm{~m}$ in the west, while in the southeast, near the Mediterranean Sea, maximum altitude is under $1500 \mathrm{~m}$. The relief isolates the valley and restricts the influence of wind flows, which gives the climate important continental characteristics, mainly aridity (Ascaso \& Casals 1981, Creus \& Ferraz 1995, Creus 1996). Annual precipitation ranges from 300 to $450 \mathrm{~mm}$ in the center of the valley and can reach $800 \mathrm{~mm}$ in the northern and southern mountainous areas. The annual mean temperature varies between 14 and $16^{\circ} \mathrm{C}$ in the bottom valley, and it is below $11^{\circ} \mathrm{C}$ in the mountainous areas. Thermal oscillation is intense. In summer, maximum temperatures easily reach $40^{\circ} \mathrm{C}$, and in winter, the minimum temperature often falls below $-10^{\circ} \mathrm{C}$ (Cuadrat 1999).

The vegetation is steppe (Suárez et al. 1992, Pedrocchi 1998), conditioned by lithology, soil and, fundamentally, aridity. There are small woods of beech trees, pine trees and oaks in the mountainous areas. The forests in the bottom of the valley have declined due to past human activity, and only some small forests remain on the slopes of the tabular relief. The main land use is unirrigated farming (wheat and barley), which makes the economy of the valley very vulnerable to a lack of precipitation. Dry years see big economic losses in the rural areas.

\section{METHODOLOGY}

In this paper, global methods (trend surfaces of different orders and empirical regression models using topographic and geographic variables as predictors), local methods (Thiessen polygons, inverse distance weighting and splines), geostatistical methods (ordinary kriging, simple kriging, directional kriging, block kriging, universal kriging and co-kriging) and mixed methods, which combine global and local or geostatistical methods, are compared for annual precipitation and temperature mapping.

\subsection{Data}

Initially, the daily data from 380 precipitation and 222 temperature stations between the years 1950 and 2000, provided by the National Institute of Meteorology (Spain), were used. This information was grouped in monthly data. Those weather stations whose location had changed by less than 2500 m were placed in the same time series, with the most recent measuring point being taken as the location. Artificial time variations were eliminated. The series were homogenized by the Alexandersson test (Alexandersson \& Moberg 1997) with reference series according to Peterson \& Easterling (1994). Annual series were created from a homogenized monthly data set. The result of the-

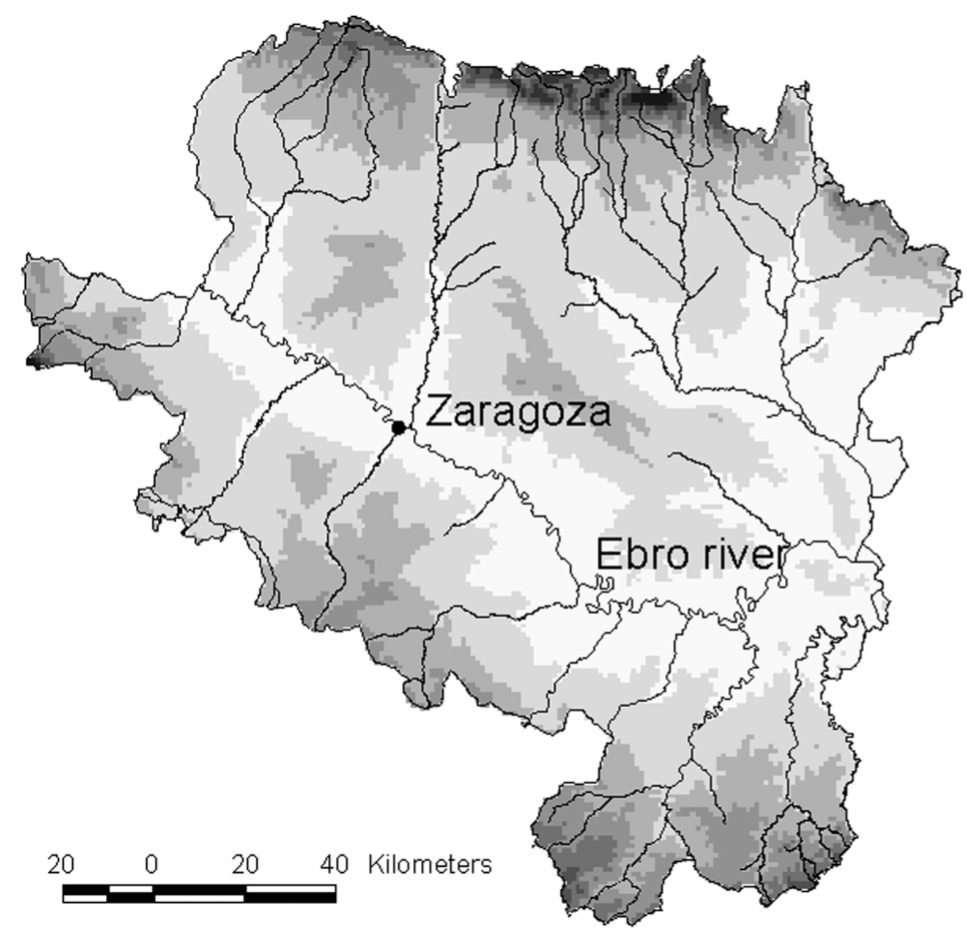

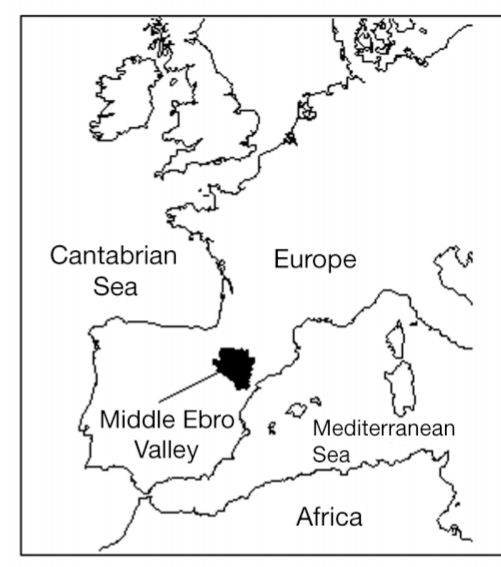

ELEVATION:
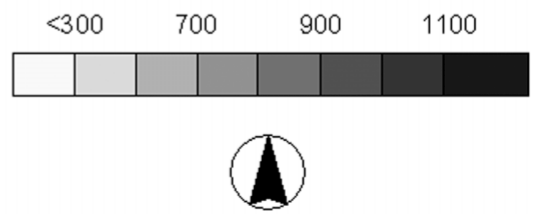

Fig. 1. Location and topography of the study area 
quality control and the homogenization process was 222 precipitation and 149 temperature series. Annual precipitation means were obtained from weather stations with more than 20 yr of annual data, and temperature means from series of over 15 yr (Ninyerola et al. 2000). The final spatial database contains 99 precipitation and 61 temperature stations, which were geographically referenced in a digital coverage at UTM30N coordinates.

Random sampling was carried out at the selected weather stations. Seventy percent of the data was used for interpolations, and the remaining $30 \%$ was reserved for subsequent tests. Fig. 2 shows the spatial distribution of weather stations used for interpolation. A cell size of 1 $\mathrm{km}$ was used for the interpolations. Brown \& Comrie (2002) and Agnew \& Palutikof (2000) used this same spatial resolution for climatic interpolation performance in the United States and the Mediterranean Basin, respectively. For regression models and mixed methods, a digital elevation model (DEM; CHE 2002: available at www.chebro.es) of the same cell size and a digital coverage of the Iberian Peninsula coastline were used.

\subsection{Global methods}

Global interpolators use all weather stations in the elaboration of climatic maps. These methods create dependence models between climatic data and other independent variables. The geographical coordinates of the weather station (latitude and longitude) and geographic (e.g. distance to water bodies) and/or topographic variables (e.g. elevation, aspect, slope, etc.) are used. The value of a climatic variable at unsampled points is predicted by the following transference function:

$$
z(x)=b_{0}+b_{1} P_{1}+b_{2} P_{2}+\ldots+b_{n} P_{n}
$$

where $z$ is the predicted value at the point $x, b_{0} \ldots b_{n}$ are the regression coefficients, and $P_{1} \ldots P_{n}$ are the values of the different independent variables at point $x$. If these variables are included in a geographic information system (GIS), they can be calculated more easily and their interrelation with climatic data can be better articulated. Global interpolators are inexact in that the values predicted by the model do not coincide with the real climatic data measured at weather stations (Borrough \& McDonnell 1998).

Two global methods were used in this paper. The first was the adjustment of several polynomial equations, using the available climatic data and the coordinates of the weather stations. Linear and non-linear relationships were analyzed, and functions (trend surfaces) of different orders were used (linear, quadratic, cubic, fourth and fifth order).

The second global method was an empirical multiple regression model using different independent variables as predictors. The relationships between climatic
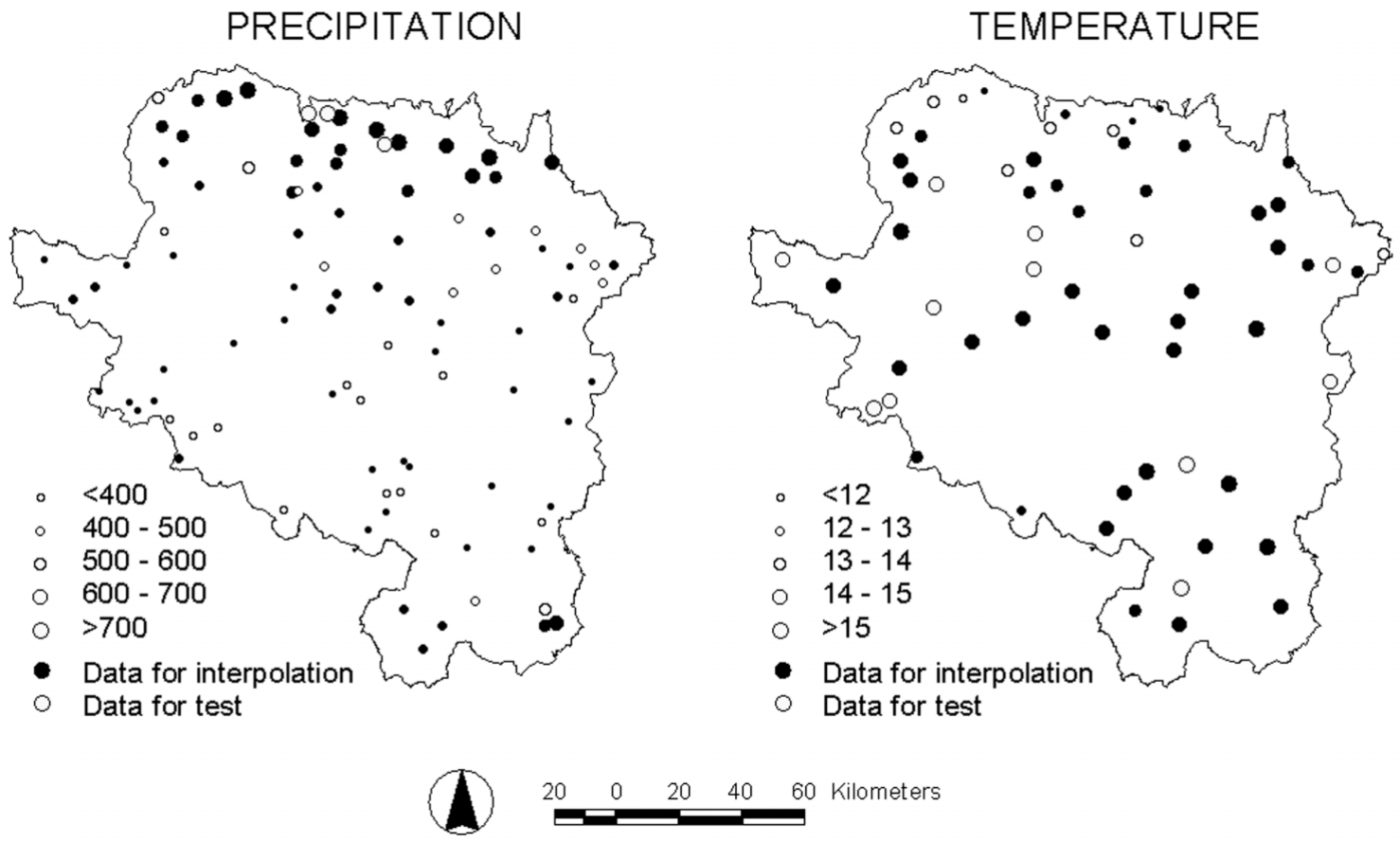

Fig. 2. Spatial distribution of weather stations. Values of annual mean precipitation $(\mathrm{mm})$ and temperature $\left({ }^{\circ} \mathrm{C}\right)$ are presented 
Table 1. Independent candidate variables for the empirical regression models

\begin{tabular}{|c|c|}
\hline $\mathrm{X}$ & Longitude \\
\hline $\mathrm{Y}$ & Latitude \\
\hline DIST_MEDIT & Distance to Mediterranean Sea \\
\hline DIST_CANT & Distance to Cantabrian Sea \\
\hline $\mathrm{RAD}^{-}$ & Incoming solar radiation (in $\mathrm{J} \mathrm{d}^{-1}$ ) \\
\hline RADx & Incoming solar radiation (in $\mathrm{J} \mathrm{d}^{-1}$ ) within $x_{i,}$ where $x$ is a radius of $2.5,5,10$ and $25 \mathrm{~km}$ \\
\hline ELEV & Elevation (in m) \\
\hline ELEVx & Mean elevation within $x_{i}$, where $x$ is a radius of $2.5,5,10$ and $25 \mathrm{~km}$ \\
\hline $\mathrm{ZXx}$ & 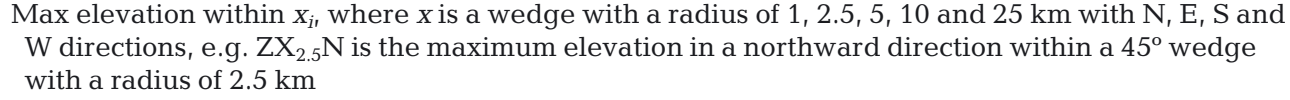 \\
\hline X_ELEV & Longitude $\times$ elevation \\
\hline Y_ELEV & Latitude $\times$ elevation \\
\hline X_DIST_MEDIT & Longitude $\times$ distance to Mediterranean Sea \\
\hline X_DIST_CANT & Longitude $\times$ distance to Cantabrian Sea \\
\hline Y_DIST_MEDIT & Latitude $\times$ distance to Mediterranean Sea \\
\hline Y_DIST_CANT & Latitude $\times$ distance to Cantabrian Sea \\
\hline X_RAD & Longitude $\times$ incoming solar radiation \\
\hline Y_RAD & Latitude $\times$ incoming solar radiation \\
\hline RAD_DIST_MEDIT & Incoming solar radiation $\times$ distance to Mediterranean Sea \\
\hline RAD_DIST_CAT & Incoming solar radiation $\times$ distance to Cantabrian Sea \\
\hline ELEV_DIST_MEDIT & Elevation $\times$ distance to Mediterranean Sea \\
\hline ELEV_DIST_CANT & Elevation $\times$ distance to Cantabrian Sea \\
\hline
\end{tabular}

data and topographic and geographic variables have been extensively analyzed throughout the scientific literature (Bonacina 1945, Tabony 1985, Basist et al. 1994, Daly et al. 1994, 2002). From these relationships, empirical models able to predict the climatic values at unsampled locations by means of the values of the geographic and topographic variables can be created. In mapping using regression-based methods, we followed a similar approach as Agnew \& Palutikof (2000) in the modeling of seasonal temperature and precipitation in the Mediterranean Basin.

Elevation is usually the main determinant of precipitation and temperature spatial distribution. Nevertheless, other variables, such as latitude, longitude, distance to water bodies, topographic shadows, slope and incoming solar radiation, may also have an important influence. The independent variables used in the middle Ebro Valley are shown in Table 1. Most of the variables were generated from the available DEM, except the distance to the Cantabrian and Mediterranean seas, which were obtained from the Iberian Peninsula coastline coverage, using the BUFFDIST module of the MiraMon GIS (Pons 1998). The latitude and longitude coverages were obtained in UTM-30N coordinates using the same software. Brown \& Comrie (2002) and Agnew \& Palutikof (2000) used a categorical variable to define the terrain aspect. This variable may be important in climate modeling because it allows for the effect of wind flows on the spatial distribution of temperature and precipitation. This categorical variable must be quantified before its inclusion in a regression model as predictor. Nevertheless, other terrain variables, such as incoming solar radiation, are spatially continuous and show the terrain aspect (northern and southern slopes have low and high incoming solar radiation values, respectively). Ninyerola et al. (2000) used this variable with excellent results when developing precipitation and temperature regression models in Catalonia (Spain). Digital coverage of annual mean incoming solar radiation was created using the MiraMon GIS and the DEM according to Pons (1997). Low-pass filters with radii of $2.5,5,10$ and $25 \mathrm{~km}$ were applied to elevation and incoming solar radiation models in order to measure the wider influence of these variables. Using the same approach as Agnew \& Palutikof (2000), and also including the effect that topographic barriers may produce on climatic variables, the Arcview v3.2 GIS was used to calculate the maximum height in a wedge of given aspect and radius. Agnew \& Palutikof (2000) emphasize that this variable is very useful in areas with dominant wind directions, because the leeward slopes are drier and warmer (Föhn effect) than windward slopes, which enables local climatic features to be identified. As in Brown \& Comrie (2002), cross products of elevation, longitude, latitude, potential incoming solar radiation, and the distances to the Cantabrian and Mediterranean seas were also calculated. These variables covered spatial variations associated with both geographic and topographic variables (e.g. mountainous areas close to the Atlantic receive higher precipitation than the mountain ranges further away). 
Table 2. Correlations (r) between precipitation and temperature and the different independent variables. Significant correlations: ${ }^{* *} 99 \%,{ }^{*} 95 \%$

\begin{tabular}{|c|c|c|}
\hline Variable & Precipitation $^{\mathrm{a}}$ & Temperature \\
\hline $\mathrm{Y}^{\mathrm{a}}$ & $0.58^{* *}$ & $-0.51^{* *}$ \\
\hline $\mathrm{X}$ & 0.07 & 0.07 \\
\hline DIST_MEDIT & $0.31^{*}$ & $-0.43^{* *}$ \\
\hline DIST_CANT & $-0.51^{* *}$ & $0.50^{* *}$ \\
\hline $\mathrm{RAD}^{\mathrm{a}}$ & $0.49^{* *}$ & $0.49^{* *}$ \\
\hline $\operatorname{RAD}_{2.5}{ }^{\mathrm{a}}$ & $0.56^{* *}$ & 0.31 \\
\hline $\mathrm{RAD}_{5}^{\mathrm{a}}$ & $0.60^{* *}$ & 0.14 \\
\hline $\mathrm{RAD}_{10}$ & $0.60^{* *}$ & $0.51^{* *}$ \\
\hline $\mathrm{RAD}_{25}$ & $0.63^{* *}$ & $0.62^{* *}$ \\
\hline ELEV & $0.80^{* *}$ & $-0.74^{* *}$ \\
\hline $\mathrm{ELEV}_{2.5}{ }^{\mathrm{a}}$ & $0.77^{* *}$ & $-0.76^{* *}$ \\
\hline $\mathrm{ELEV}_{5}{ }^{\mathrm{a}}$ & $0.78^{* *}$ & $-0.76^{* *}$ \\
\hline $\mathrm{ELEV}_{10}{ }^{\mathrm{a}}$ & $0.77^{* *}$ & $-0.75^{* *}$ \\
\hline $\mathrm{ELEV}_{25}{ }^{\mathrm{a}}$ & $0.77^{* *}$ & $-0.75^{* *}$ \\
\hline $\mathrm{ZX}_{2.5} \mathrm{~N}^{\mathrm{a}}$ & $0.73^{* *}$ & $-0.74^{* *}$ \\
\hline $\mathrm{ZX}_{5} \mathrm{~N}$ & $0.66^{* *}$ & $-0.71^{* *}$ \\
\hline $\mathrm{ZX}_{10} \mathrm{~N}^{\mathrm{a}}$ & $0.51^{* *}$ & $-0.61^{* *}$ \\
\hline $\mathrm{ZX}_{25} \mathrm{~N}^{\mathrm{a}}$ & 0.23 & $-0.43^{* *}$ \\
\hline $\mathrm{ZX}_{2.5} \mathrm{E}^{\mathrm{a}}$ & $0.74^{* *}$ & $-0.75^{* *}$ \\
\hline $\mathrm{ZX}_{5} \mathrm{E}^{\mathrm{a}}$ & $0.73^{* *}$ & $-0.71^{* *}$ \\
\hline $\mathrm{ZX}_{10} \mathrm{E}^{\mathrm{a}}$ & $0.66^{* *}$ & $-0.64^{* *}$ \\
\hline $\mathrm{ZX}_{25} \mathrm{E}^{\mathrm{a}}$ & $0.57^{* *}$ & $-0.54^{* *}$ \\
\hline $\mathrm{ZX}_{2.5} \mathrm{~S}^{\mathrm{a}}$ & $0.81^{* *}$ & $-0.75^{* *}$ \\
\hline $\mathrm{ZX}_{5} \mathrm{~S}^{\mathrm{a}}$ & $0.82^{* *}$ & $-0.72^{* *}$ \\
\hline $\mathrm{ZX}_{10} \mathrm{~S}^{\mathrm{a}}$ & $0.83^{* *}$ & $-0.69^{* *}$ \\
\hline $\mathrm{ZX}_{25} \mathrm{~S}^{\mathrm{a}}$ & $0.79^{* *}$ & $-0.66^{* *}$ \\
\hline $\mathrm{ZX}_{2.5} \mathrm{~W}^{\mathrm{a}}$ & $0.81^{* *}$ & $-0.77^{* *}$ \\
\hline $\mathrm{ZX}_{5} \mathrm{~W}^{\mathrm{a}}$ & $0.82^{* *}$ & $-0.79^{* *}$ \\
\hline $\mathrm{ZX}_{10} \mathrm{~W}^{\mathrm{a}}$ & $0.81^{* *}$ & $-0.74^{* *}$ \\
\hline $\mathrm{ZX}_{25} \mathrm{~W}^{\mathrm{a}}$ & $0.80^{* *}$ & $-0.70^{* *}$ \\
\hline X_ELEV ${ }^{a}$ & $0.79^{* *}$ & $-0.75^{* *}$ \\
\hline Y_ELEV & $0.82^{* *}$ & $-0.75^{* *}$ \\
\hline X_DIST_MEDIT ${ }^{\mathrm{a}}$ & $0.31^{*}$ & $-0.49^{* *}$ \\
\hline X_DIST_CANT ${ }^{a}$ & $-0.52^{* *}$ & $0.47^{* *}$ \\
\hline Y_DIST_MEDIT & $0.32^{*}$ & $-0.43^{* *}$ \\
\hline Y_DIST_CANT & $-0.52^{* *}$ & $0.50^{* *}$ \\
\hline X_RAD & 0.21 & -0.07 \\
\hline Y_RAD ${ }^{a}$ & $0.59^{* *}$ & $-0.60^{* *}$ \\
\hline RAD_DIST_MEDIT & $0.35^{* *}$ & $-0.45^{* *}$ \\
\hline RAD_DIST_CANT & $-0.51^{* *}$ & $0.49^{* *}$ \\
\hline ELEV_DIST_MEDIT & $0.72^{* *}$ & $-0.75^{* *}$ \\
\hline ELEV_DIST_CANT ${ }^{\mathrm{a}}$ & $0.29^{*}$ & $-0.37^{*}$ \\
\hline
\end{tabular}

The normality of each variable was tested by the Kolmogorov-Smirnoff test, and natural logarithms were applied where necessary in order to fit a normal distribution more closely. Correlations between mean precipitation and temperature and the different geographic and topographic variables are shown in Table 2. Variables transformed using natural logarithms are identified. A stepwise multiple regression analysis, using SPSS v.8.0 statistical software, was performed with precipitation and temperature as dependent variables and topographic and geographic variables as predictors. The amount of variance explained and the variables introduced in both models are shown in Table 3. The precipitation model explains $91 \%$ of the variance and has 4 variables: $\mathrm{ZX}_{5} \mathrm{~N}, \mathrm{Y}$, Y_DIST_CANT and ELEV $_{25}$. The temperature model shows similar variance $(89 \%)$, but has 5 variables: ZX X $_{5}$, X_DIST_MEDIT, $\mathrm{ZX}_{5} \mathrm{~S}, \mathrm{ZX}_{25} \mathrm{~S}$ and X_ELEV. The relative importance of the predictor variables is shown in Table 4 using the standardized (beta) coefficients. The final climatic maps were obtained using Arcview v3.2 GIS.

\subsection{Local interpolation methods}

In global methods, local variations are dismissed as random, unstructured noise, and the climatic map is created on the basis of the general structure of the variable at all available points (Borrough \& McDonnell 1998). Other methods, such as local interpolators, only use the data of the nearest sampling points for climatic mapping. A number of weather stations, $z\left(x_{1}\right), z\left(x_{2}\right), \ldots$, $z\left(x_{n}\right)$, around the unsampled point $z(x)$ are selected, and a mathematical function, which represents the variation of the climatic variable across the selected points, is formulated. This function is applied at $z(x)$ to predict its climatic value (Borrough \& McDonnell 1998), and the process is repeated until climatic values at all points (cells of the grid) have been calculated.

Three local methods were used in this paper: Thiessen polygons, inverse distance weighting and splines. These methods are exact spatial interpolators, as predictions coincide with the values measured at the weather stations. The first local method (Thiessen polygons or nearest neighbors) predicts the climatic values at unsampled locations by taking the value of the nearest point where climatic information is available. It is a very simple approach, since the result is a polygon network conditioned by the spatial distribution of the weather stations, with abrupt spatial discontinuities in the values when passing from one polygon to another. Borrough \& McDonnell (1998) emphasize that Thiessen polygon interpolation is not appropriate for variables with gradual spatial variation, such as precipitation and temperature.

Table 3. Results of the stepwise multiple regression analysis

\begin{tabular}{|cccc|}
\hline & $\mathrm{r}$ & $\mathrm{r}^{2}$ & Variables \\
\hline Precipitation & 0.95 & 0.91 & ZX $_{5} \mathrm{~N}, \mathrm{Y}, \mathrm{Y}$ _DIST_CANT, ELEV \\
Temperature & 0.94 & 0.89 & ZX $_{5}$ W, X_DIST_MEDIT, ZX \\
& & & \\
\hline
\end{tabular}


Table 4. Significant standardized (beta) coefficients of the independent variables included in the regression models for temperature and precipitation

\begin{tabular}{|lc|}
\hline Variable & Standardized (beta) coefficient \\
\hline Precipitation & \\
ZX & \\
Y & 0.41 \\
Y_DIST_CANT & 0.64 \\
ELEV $_{25}$ & -0.75 \\
Temperature & 0.27 \\
ZX $_{5}$ W & \\
X_DIST_MEDIT $_{\text {ZX }_{5} S}$ & -1.13 \\
ZX & \\
X_ELEV & -0.31 \\
& 1.12 \\
\hline
\end{tabular}

The second local method (inverse distance weighting interpolation) is based on the assumption that the climatic value at unsampled point $z(x)$ is a distanceweighted average of the climatic values at sampling points $z\left(x_{1}\right), z\left(x_{2}\right), \ldots, z\left(x_{n}\right)$, included in a radius around $z(x)$. The distance $\left(d_{i}\right)$ between $z\left(x_{i}\right)$ and $z(x)$ is the weighting factor because, generally, climatic values are more alike between the nearest points than between distant points. This supposes that predictions are obtained from the nearest sampling points.

$$
z(x)=\frac{\sum_{i=1}^{n} z\left(x_{i}\right) \times d_{i j}^{-r}}{\sum_{i=1}^{n} d_{i j}^{-r}}
$$

where $z(x)$ is the predicted value; $z\left(x_{i}\right)$ is the climatic value of a neighboring weather station; $d_{i j}$ is the distance between $z(x)$ and $z\left(x_{i}\right)$; and $r$ is the exponent of the distance. Maps with $r=1,2$ and 3 were created.

The third local method used was splines. This method is based on a family of continuous, regular and derived functions adapted to the local variations of climatic data. Splines are similar to the equations obtained from the trend surfaces or regression-based methods. The differences are that splines are not obtained from all available weather stations but from specific points defined by a radius around $z(x)$ and that they are an exact interpolator because the functions are adapted to the climatic values at the sampled points. Smoothing or tension parameters can be introduced into the models, giving more or less smoothed maps, but with predicted values always coinciding with those observed at the weather station. For each $z(x)$, a new function is created according to the available sampling points within radius $r$. The functions are adapted to the sampling points without loss of continuity properties, because each function has an important role in a particular region and a null weight outside.
The predicted value $z(x)$ is determined by 2 terms:

$$
z(x)=T(x)+\sum_{i=1}^{n} \lambda_{j} \times \psi_{j}\left(r_{i}\right)
$$

$T(x)$ is a polynomial smoothing term, and the second term groups a series of radial functions, where $\psi_{j}\left(r_{i}\right)$ are a known group of functions, and $\lambda_{j}$ represents the parameters whose explanation is given in Mitasova et al. (1995).

$$
\psi\left(r_{i}\right)=-\left[\ln \left(\frac{\varphi \times r_{i}}{2}\right)+E_{i} \times\left(\frac{\varphi \times r_{i}}{2}\right)+C_{E}\right]
$$

where $\varphi$ is the tension coefficient; $C_{\mathrm{E}}$ is the Euler constant $(0.577215 \ldots) ; E_{i}$ is the exponential integral function; and

$$
r_{i}=\sqrt{\left(x-x_{i}\right)^{2}+\left(y-y_{i}\right)^{2}}
$$

Spline algorithms are mathematically quite complex but are standard in current GIS software. In this paper the various spline interpolations were made using the INTERPNT module of the MiraMon GIS. Tension and smoothing parameters $\varphi=400, \varphi=5000, T(x)=0$ and $T(x)=400$ were used.

\subsection{Geostatistical methods}

Geostatistical interpolation methods (or kriging) assume that the spatial variation of a continuous climatic variable is too irregular to be modeled by a mathematical function, and its spatial variation could be better predicted by a probabilistic surface. This continuous variable is called a regionalized variable, which consists of a drift component and a random but spatially correlated component. The climatic value at point $z(x)$ is expressed by (Borrough \& McDonnell 1998):

$$
z(x)=m(x)+\varepsilon^{\prime}(x)+\varepsilon^{\prime \prime}
$$

where $m(x)$ is the drift component that indicates the structural variation of the climatic variable and $\varepsilon^{\prime}(x)$ are the residuals, i.e. the difference between the drift component and the sampling data values. These residuals are spatially dependent, whereas $\varepsilon^{\prime \prime}(x)$ indicates the spatially independent residuals. The predictions obtained using kriging methods are based on a weighted average of the data available in the $n$ neighboring weather stations. The weighting is chosen so that the calculation is not biased and variance is minimum. Initially, a function that relates the spatial variance of the climatic variable must be determined using a semi-variogram model that adjusts the semi-variances between the climatic values at different spatial distances. 
There are different types of kriging, and several papers describe them in detail (Isaaks \& Strivastava 1989, Goovaerts 1997, Borrough \& McDonnell 1998). Various geostatistical methods were used in this paper for temperatures and precipitation interpolation (simple kriging, ordinary kriging, directional kriging, block kriging, universal kriging and co-kriging with elevation as covariant). The GSTAT program (Pebesma \& Wesseling 1998) was used in variogram estimations and final interpolations. Precipitation and temperature semivariograms and cross-semivariograms, using elevation as covariant, are shown in Fig. 3.

\subsection{Mixed methods}

Global methods are inexact interpolators, since the predicted value $z(x)$ does not coincide with the real climatic data recorded at the weather stations. There is a known error in the final prediction (residual). Ninyerola et al. (2000), Agnew \& Palutikof (2000), Brown \& Comrie (2002), among others, used a correction method (interpolation of residuals) to obtain exact climatic data from the weather stations:

$$
\text { residual }=\text { observed data }- \text { predicted data }
$$

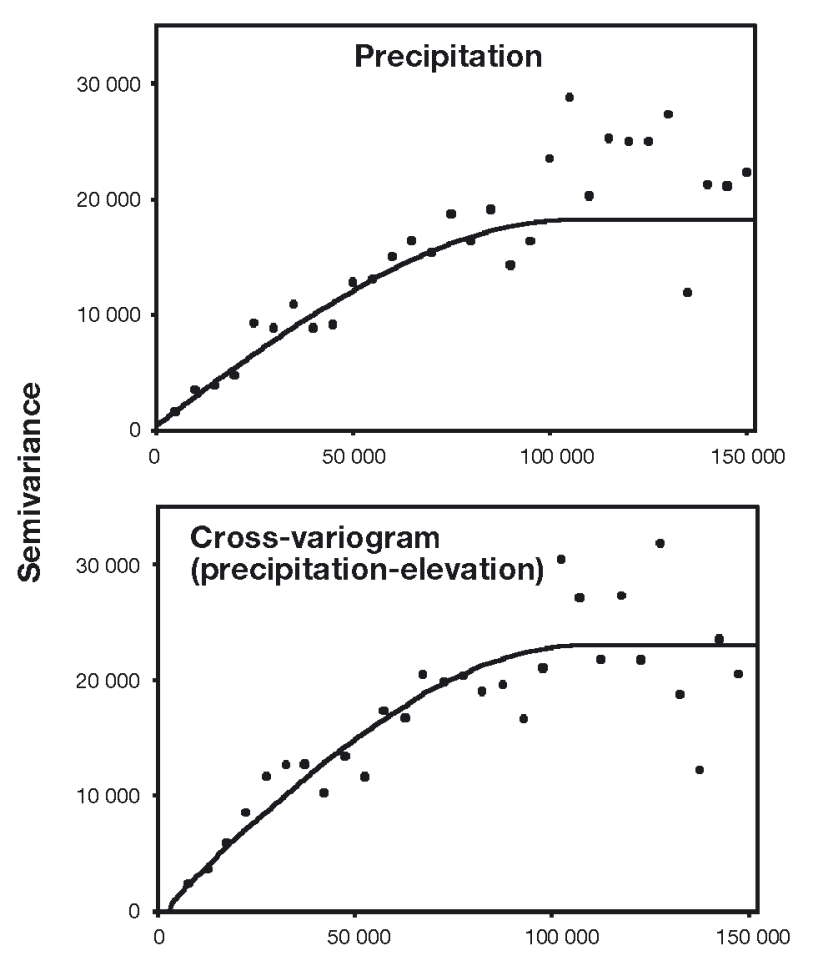

The residuals must be interpolated to obtain correction maps. Inverse distance weighting $(r=2)$ and splines with tension $(\varphi=400)$ were used to interpolate the residuals of the temperature and precipitation maps created by means of a regression-based method. The sum of residual interpolation and predicted regression maps modifies the initial results of the model, and real values can be obtained at the locations of the weather stations:

$$
\begin{aligned}
\text { observed data }= & \text { predicted data }+ \\
& \text { residual interpolation }
\end{aligned}
$$

Lastly, we applied a final interpolation method to temperature mapping. Smart interpolation (Willmott \& Matsuura 1995) only uses elevation, as auxiliary data, in the interpolation of temperatures, because of the close relationship between the spatial distribution of the 2 variables. This method assumes a constant influence of elevation within the entire study area and starts with a temperature reduction at sea level, which can be calculated from

$$
{ }_{\mathrm{s}} T_{i}=T_{i}+\Gamma z_{i}
$$

where $T_{i}$ is annual average air temperature at weather Stn $i_{i} \Gamma$ is average environmental lapse rate, which, according to Willmott \& Matsuura (1995), is $6.5 \times 10^{-3}{ }^{\circ} \mathrm{C}$ $\mathrm{m}^{-1} ; z_{i}$ is the elevation of $\operatorname{Stn} i_{i}$ and ${ }_{\mathrm{s}} T_{i}$ is the predicted annual average air temperature at sea level for Stn $i$. Later,
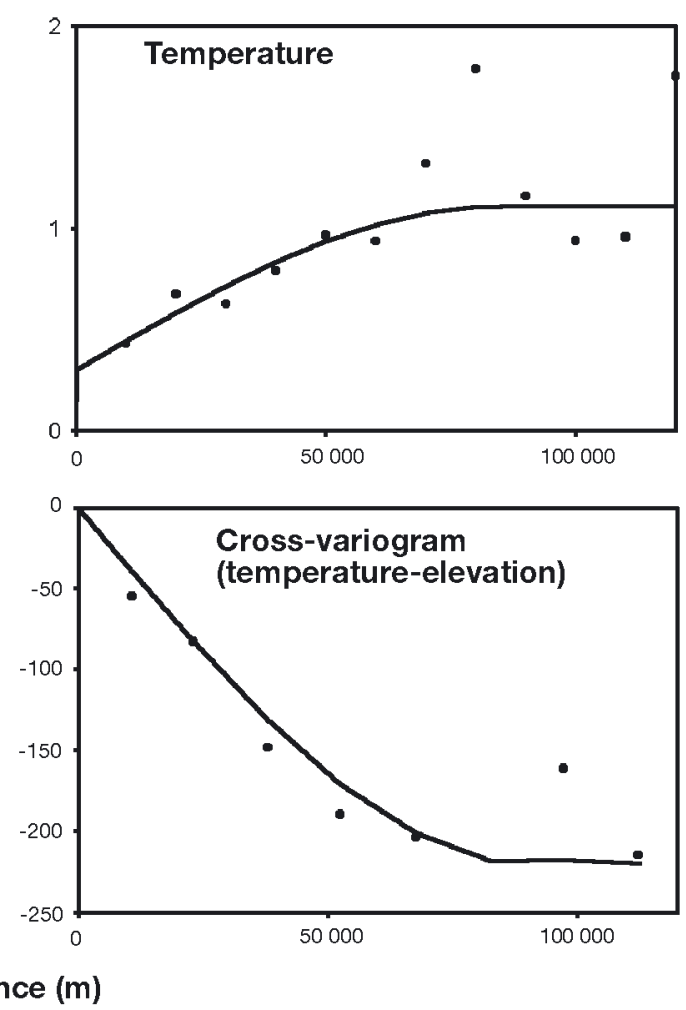

Fig. 3. Semivariogram models for precipitation and temperature, and cross-semivariogram models for precipitation versus elevation and temperature versus elevation 
the values of ${ }_{\mathrm{s}} T_{i}$ are interpolated using local methods. In this paper 2 methods were used to obtain an average air temperature map at sea level: inverse distance weighting interpolation $(r=2)$ and splines with tension $(\varphi=$ $400)$. Finally, the air temperature at grid point $j$ is predicted using its elevation value, according to:

$$
T_{j i}={ }_{\mathrm{s}} T_{j i}-\Gamma z_{j i}
$$

where $T_{j i}$ is the predicted value at grid point $i$, and $z_{j i}$ is the elevation at grid point $i$.

\subsection{Test and validation of climatic maps}

Temperature and precipitation maps must be assessed by statistics that indicate the degree of concordance between models and reality. Following Willmott's (1982) suggestion, we determined, through various statistical calculations, the error between predictions obtained by the different interpolation methods and the real data recorded at the weather stations. Table 5 shows these measurements, which include the coefficient of determination $\left(\mathrm{r}^{2}\right)$ between real and predicted data as a first calculation of the reliability of the model, and the intercept-slope pair to indicate whether or not there is a bias in the models. These measurements give a preliminary idea of the model's validity. Nevertheless, Willmott (1982) emphasized that the relationship between $\mathrm{r}^{2}$ and model performance is not well defined, and the magnitudes of $\mathrm{r}^{2}$ are not consistently related to the accuracy of prediction. For this reason, other statistics were used to determine the performance of each model, such as mean bias error (MBE), mean absolute error (MAE) and rootmean-square error (RMSE). Willmott (1982) suggests that RMSE and MAE are among the 'best' overall measures of model performance, as they summarize the mean difference in the units of observed and predicted values. The problem is that RMSE provides a measurement of model validity that places a lot of weight on high errors, whereas MAE is less sensitive to extreme values. Other accuracy measurements were also used to test the temperature and precipitation models. Model efficiency (EF), proposed by Greenwood et al. (1985), is calculated on the basis of the relationship between the observed and predicted mean deviations. If EF is close to zero, it indicates that the mean value of the observations is more reliable than the predictions, and the model has important limitations. Finally, a relative and bounded measure of model validity was used. The agreement index $\left(D_{\text {; }}\right.$ Willmott 1981) was used, because it scales with the magnitude of the variables, retains mean information and does not amplify outliers.

Nevertheless, not only statistical criteria were used to determine the validity of the interpolated climatic maps. Daly et al. (2002) emphasized that subjective
Table 5. Statistical criteria used to assess the agreement of the models

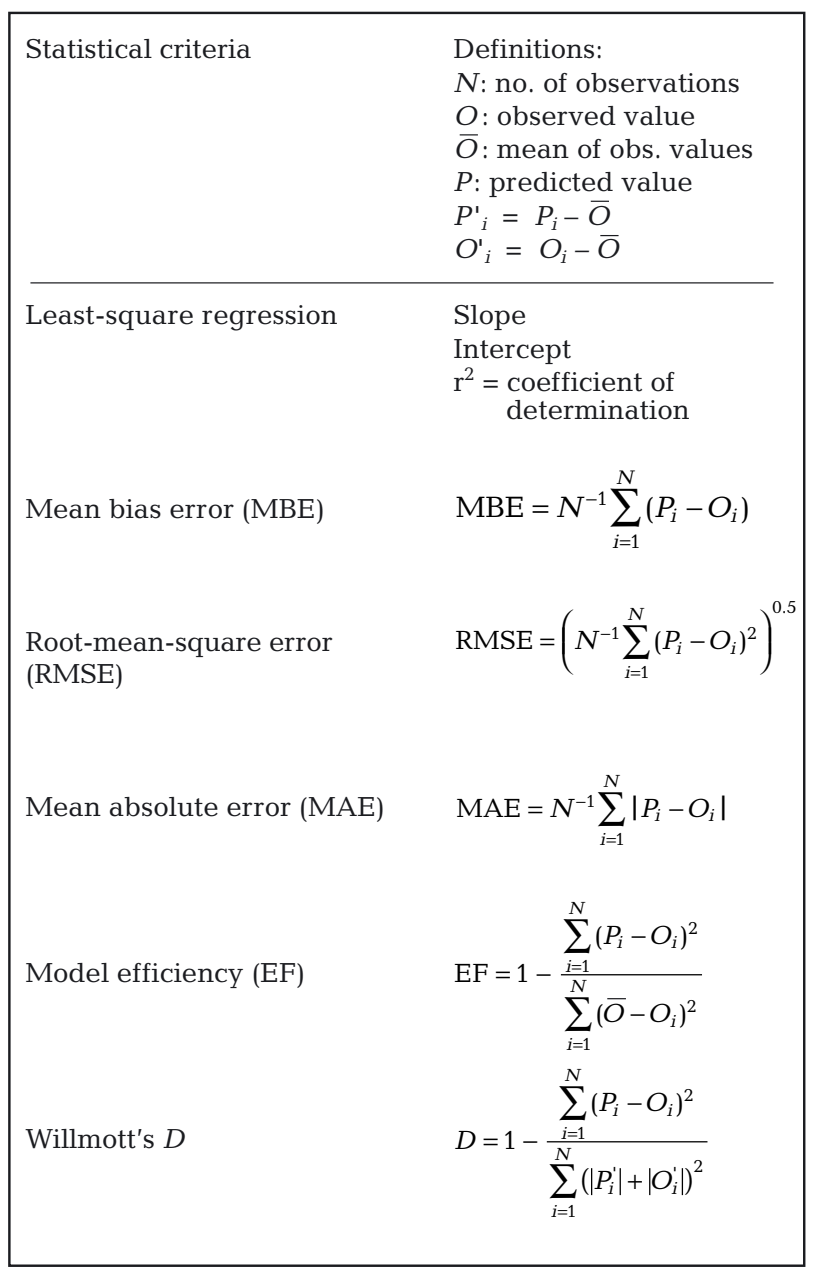

evaluation of the reasonableness of the maps is worthwhile. Direct empirical climatic knowledge can help determine the models that reflect reality best, as long as their statistical values are reasonable. Therefore, subjective comments, based on our knowledge of spatial distribution of precipitation and temperature in the middle Ebro Valley, were also added.

\section{RESULTS}

\subsection{Precipitation maps}

Twelve representative examples of the 23 precipitation maps created are shown in Fig. 4. Some common spatial patterns can be observed. A clear north-south precipitation gradient exists in all the maps, with high precipitation in the north due to the greater influence of the Atlantic disturbances there than in the rest of the study area. The characteristic dryness in the center of the 

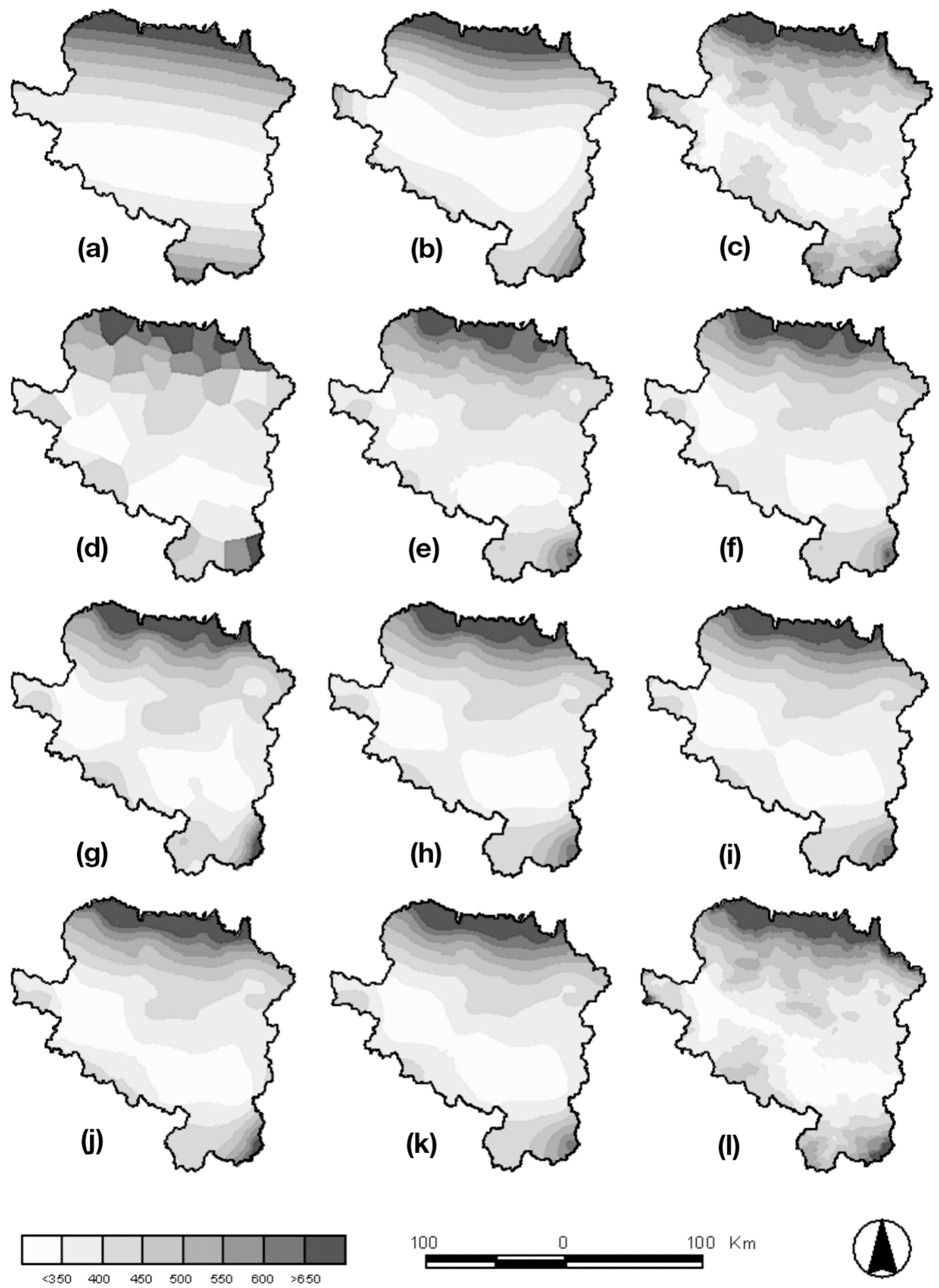

100

0

$100 \mathrm{Km}$

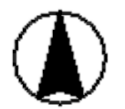

Fig. 4. Results of interpolation methods for annual mean precipitation (mm). (a) Trend surface (second order); (b) trend surface (fourth order); (c) regression model; (d) Thiessen polygons; (e) inverse distance weighting $(r=2)$; (f) splines with tension; (g) smoothing splines; (h) ordinary kriging; (i) block kriging; (j) universal kriging with quadratic drift; (k) co-kriging; (l) regression model + residuals (inverse distance, $r=2$ ) 
valley, where annual precipitation is less than $350 \mathrm{~mm}$, is well reflected too. The transition between the 2 climatic environments is very abrupt, with close parallel precipitation bands on all the maps. There is also a northwest-southeast transition, though less abrupt than the north-south one, caused by the greater influence of the Mediterranean flows over the eastern areas. Spatial differences between the different models were also detected. The trend surface maps (Fig. $4 \mathrm{a}, \mathrm{b}$ ) indicate the general patterns of precipitation distribution in the study area. How well they reflect reality is conditioned by the polynomial order of the function used. Nevertheless, both maps smooth the real distribution of precipitation too much. In reality, it is more complex spatially.

The multiple regression model (Fig. 4c) shows more spatial diversity, determined by the richness that the inclusion of topographic and geographic variables gives to performance prediction. This model also shows the north-south gradient, but with more spatial details, generated by the relief configuration. Higher precipitation values are recorded in the tabular relief in the center of the valley, and more spatial differences than in the other models are seen in mountainous areas.

The Thiessen polygons map (Fig. 4d) shows an unreal spatial distribution of precipitation, with abrupt limits between precipitation areas caused by the location of the stations. Other local interpolators, such as inverse distance weighting and splines, are very different from the Thiessen polygon model. The spatial smoothing is greater using splines (Fig. 4g) with visual patterns similar to higher-order trend surface models. The 4 geostatistical methods (ordinary kriging, block kriging, universal kriging with quadratic drift and cokriging) differ little visually from each other. However, greater spatial extension of low-precipitation areas $(<350 \mathrm{~mm})$ is seen in the co-kriging (Fig. $4 \mathrm{k})$ and block kriging maps (Fig. 4i). Finally, the regression model, corrected with residuals (Fig. 41), differs little visually from the original map (Fig. 4c).

The differences between predicted values and observed mean annual precipitation in test stations are shown in Fig. 5. The straight $45^{\circ}$ line indicates absolute coincidence between observed and predicted data. A first approach to the accuracy of the models is determined using the coefficient of determination $\left(\mathrm{r}^{2}\right)$ between observed and predicted data on the different maps. In general, there are few differences between them (Table 6), but the lowest coefficients are observed in the second-order trend surface $\left(\mathrm{r}^{2}=0.82\right)$, Thiessen polygons $\left(r^{2}=0.86\right)$ and inverse distance weighting maps $\left(\mathrm{r}^{2}=0.90\right)$. The regression map and the different kriging models show the highest coefficients of determination between real and predicted data $\left(\mathrm{r}^{2}=0.95-0.96\right)$. However, in general, observed and predicted data are similar in most of the models.
The results of the accuracy measurements in the different precipitation models are shown in Table 6 . The first- and second-order trend surfaces and the map created from the Thiessen polygon method can be considered the worst models in statistical terms. These models give the higher values of RMSE and MAE and lower coefficients of determination between observed and predicted data. EF and $D$ indicate poor results using these methods, especially in the case of the first-order trend surface $(E F=0.25$, $D=0.71$ ).

The differences in accuracy measurements between third- and fourth-order trend surfaces and the regression model are small. The coefficients of determination are similar in the 3 cases $\left(r^{2}=0.94\right.$ to 0.95$)$, as are the model efficiency $(\mathrm{EF}=0.94)$ and agreement $(D=0.99)$ indices. The regression model has a lower RMSE value than other general methods; nevertheless the MAE value is lower in the third- and fourth-order trend surfaces. This supposes that trend surfaces show the general spatial patterns of precipitation distribution (indicated by low MAE values), but that higher differences than in the regression model are recorded at determined points, because RMSE is more sensitive to extremes.

Of the local methods, different spline techniques produce the lowest errors, comparable to the errors found with higher-order trend surfaces and the regression model. Inverse distance weighting, whatever the exponent used, and the Thiessen polygon maps have high error values which do not qualify them for precipitation mapping in the middle Ebro Valley. The different kriging models show lower error values than the rest of the methods used in precipitation mapping (e.g. the models obtained by block kriging and co-kriging show MAE values of 15.80 and $16.19 \mathrm{~mm}$, respectively), and the differences between them are small, with good general results in all cases.

Finally, the regression map corrected using residual interpolation shows error values similar to those in the original model. Nevertheless, the RMSE and MAE statistics are slightly higher, while EF and $D$ values are lower.

According to the statistical results, the different precipitation models indicate, in general, good results. There are few differences between the maps. There are, however, some methods that should be rejected at once due to their unrealistic approximation of real data (Thiessen polygons and first-order trend surfaces). Local methods (especially inverse distance weighting) also conflict with reality and show marked differences with global and geostatistical methods, with the latter having less statistical error (RMSE and MAE), and greater EF and $D$ with real data. 

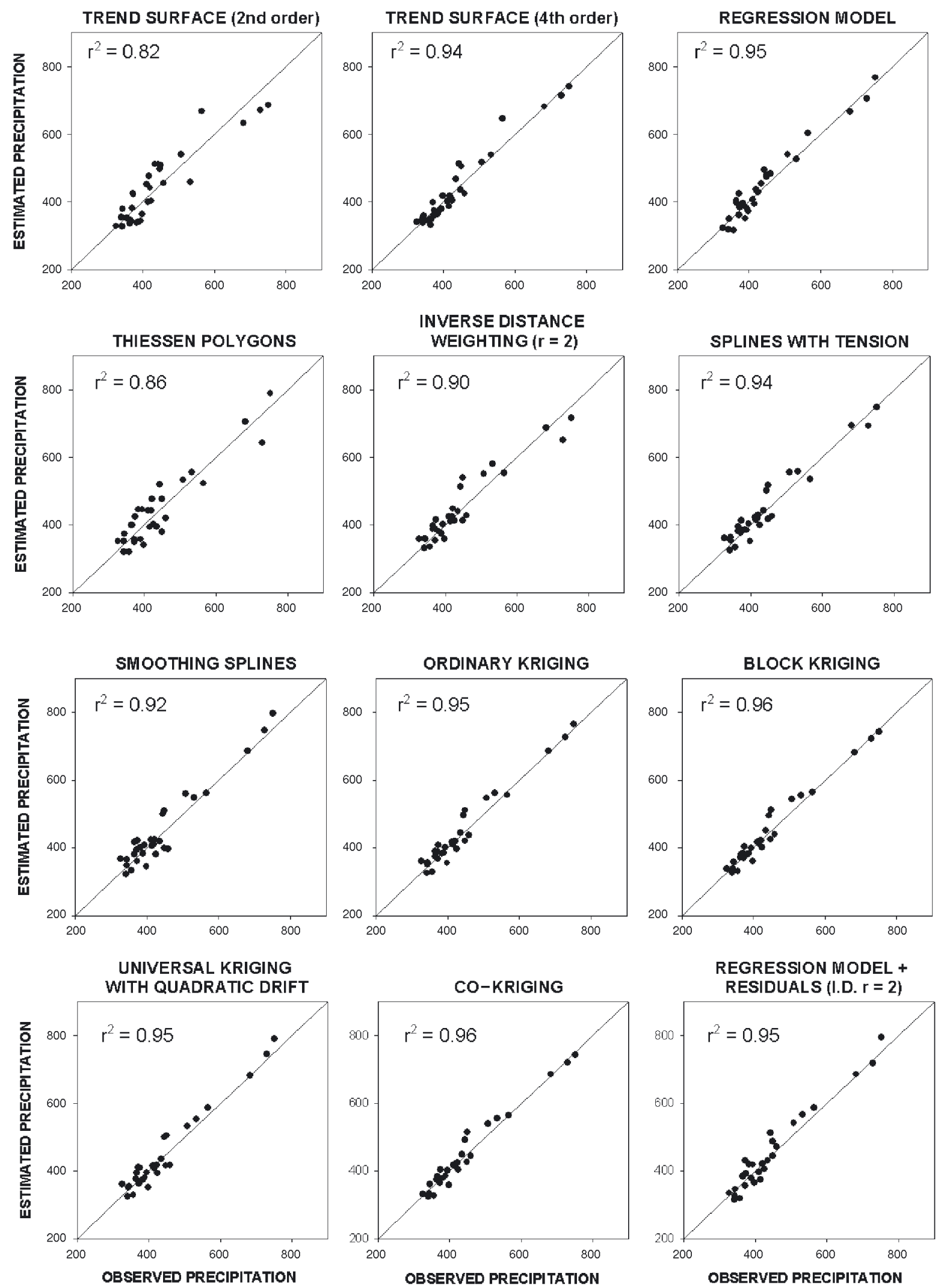

Fig. 5. Differences between observed and predicted values for precipitation $(\mathrm{mm})$ in different models 


\subsection{Temperature maps}

Twelve representative examples of the 25 annual mean temperature maps are shown in Fig. 6. The general spatial patterns are more complex than those in the precipitation maps, although a north-south gradient is also detected. Coldest temperatures are found in the north of the study area, while high thermal values are shown in the center of the valley, coinciding with the lowest elevation areas. Low thermal values also appear in the southeast, coinciding again with a mountainous relief. Large spatial differences between the diverse interpolated maps are observed. Trend surface interpolations (Fig. 6a) indicate the general distribution of temperatures in the study area, with high thermal values in the center of the valley and low temperatures in the north and southeast mountainous chains. The Smart interpolation (Fig. 6b) shows a spatial distribution of temperatures mainly determined by the topography of the study area. The highest elevations have the lowest mean temperatures $\left(T<12^{\circ} \mathrm{C}\right)$, whereas lower areas have the highest. Although the multiple regression model (Fig. 6c) also shows a certain relief incidence, the spatial distribution of temperatures is not explained just by elevation, as in the Smart interpolation model. In the regression model map, the highest elevations (northern sector) also have the lowest temperature values, but there are areas where the elevation increase is not accompanied by a decrease in thermal values (NW areas and eastern relief). The inclusion of other geographic and topographic variables, mainly distance from water, introduces an aspect which was ignored by the Smart interpolation, but improves the prediction. The regression model map shows that being closer to the Mediterranean Sea determines higher temperatures in the eastern areas, which means that elevation is not the only variable affecting the spatial distribution of temperatures in the middle Ebro Valley.

The Thiessen polygon map (Fig. 6d) is chaotic and far removed from our empirical knowledge of the distribution of temperatures in the valley. The inverse distance weighting (Fig. 6e) and spline methods (Fig. 6f,g) give great spatial heterogeneity, with some marked 'fried egg' effects as a consequence of the spatial distribution of stations. The temperature distribution is highly smoothed in these models, which do not reflect the real spatial diversity that relief produces. Despite this, lower thermal values are also shown in the mountainous northern relief, and higher values in the eastern areas nearest to the Mediterranean. Similar maps are obtained by the different kriging methods, although these maps show higher smoothness in temperature values than local interpolations. The results of the different geostatistical methods vary considerably. The map obtained by means of universal kriging with quadratic

Table 6. Accuracy measurements for precipitation models. Mean, MBE, RMSE and MAE are expressed in mm

\begin{tabular}{|c|c|c|c|c|c|c|c|c|c|}
\hline Model & Mean & $r^{2}$ & Slope & Intercept & RMSE & $\mathrm{MBE}$ & MAE & $\mathrm{EF}$ & $D$ \\
\hline Trend surface (first order) & 455.84 & 0.30 & 0.39 & 284.61 & 94.24 & 15.17 & 78.42 & 0.25 & 0.71 \\
\hline Trend surface (second order) & 444.71 & 0.82 & 0.89 & 54.28 & 46.73 & 4.04 & 39.96 & 0.81 & 0.95 \\
\hline Trend surface (third order) & 438.87 & 0.95 & 1.04 & -18.43 & 27.26 & -1.80 & 22.09 & 0.94 & 0.99 \\
\hline Trend surface (fourth order) & 442.77 & 0.94 & 1.02 & -6.39 & 27.50 & 2.11 & 20.16 & 0.94 & 0.98 \\
\hline Trend surface (fifth order) & 441.40 & 0.93 & 1.03 & -11.46 & 30.42 & 0.73 & 22.73 & 0.92 & 0.98 \\
\hline Regression model & 446.12 & 0.95 & 1.01 & 0.80 & 26.13 & 5.45 & 22.38 & 0.94 & 0.99 \\
\hline Thiessen polygons & 444.46 & 0.86 & 0.94 & 29.97 & 41.81 & 3.80 & 37.53 & 0.85 & 0.96 \\
\hline Inverse distance weighting $(r=1)$ & 446.14 & 0.88 & 0.79 & 99.25 & 39.35 & 5.48 & 30.21 & 0.87 & 0.96 \\
\hline Inverse distance weighting $(r=2)$ & 446.57 & 0.90 & 0.90 & 49.89 & 34.49 & 5.90 & 26.73 & 0.90 & 0.97 \\
\hline Inverse distance weighting $(r=3)$ & 446.58 & 0.89 & 0.95 & 27.61 & 37.08 & 5.91 & 29.84 & 0.88 & 0.97 \\
\hline Splines with tension $(\varphi=400)$ & 446.47 & 0.94 & 0.95 & 25.99 & 28.29 & 5.80 & 22.46 & 0.93 & 0.98 \\
\hline Splines with tension $(\varphi=5000)$ & 445.35 & 0.93 & 0.87 & 60.95 & 29.98 & 4.68 & 23.80 & 0.92 & 0.98 \\
\hline Smoothing splines $[T(x, y)=0]$ & 447.24 & 0.92 & 1.04 & -10.00 & 33.36 & 6.57 & 27.06 & 0.91 & 0.98 \\
\hline Smoothing splines $[T(x, y)=400]$ & 452.95 & 0.95 & 0.91 & 52.21 & 27.25 & 12.28 & 20.98 & 0.94 & 0.98 \\
\hline Simple kriging & 444.12 & 0.96 & 0.99 & 7.18 & 22.52 & 3.45 & 16.55 & 0.96 & 0.99 \\
\hline Ordinary kriging & 446.27 & 0.95 & 1.01 & 1.10 & 24.49 & 5.61 & 18.46 & 0.95 & 0.99 \\
\hline Block kriging & 444.40 & 0.96 & 1.00 & 4.40 & 22.03 & 3.74 & 15.80 & 0.96 & 0.99 \\
\hline Ordinary kriging with anisotropy & 443.64 & 0.95 & 0.89 & 51.96 & 25.86 & 2.97 & 19.71 & 0.94 & 0.98 \\
\hline Universal kriging with linear drift & 447.86 & 0.95 & 1.03 & -7.11 & 26.10 & 7.19 & 20.51 & 0.94 & 0.99 \\
\hline Universal kriging with quadratic drift & 446.22 & 0.95 & 1.05 & -15.40 & 27.12 & 5.55 & 21.55 & 0.94 & 0.99 \\
\hline Co-kriging & 444.11 & 0.96 & 1.00 & 2.13 & 22.11 & 3.44 & 16.18 & 0.96 & 0.99 \\
\hline $\begin{array}{l}\text { Regression model }+ \text { residuals } \\
\text { (inverse distance, } r=2 \text { ) }\end{array}$ & 447.78 & 0.95 & 1.06 & -17.42 & 28.21 & 7.11 & 22.57 & 0.93 & 0.98 \\
\hline $\begin{array}{l}\text { Regression model }+ \text { residuals } \\
\text { (splines with tension, } \varphi=400 \text { ) }\end{array}$ & 448.23 & 0.95 & 1.07 & -23.55 & 29.60 & 7.56 & 23.43 & 0.93 & 0.98 \\
\hline
\end{tabular}



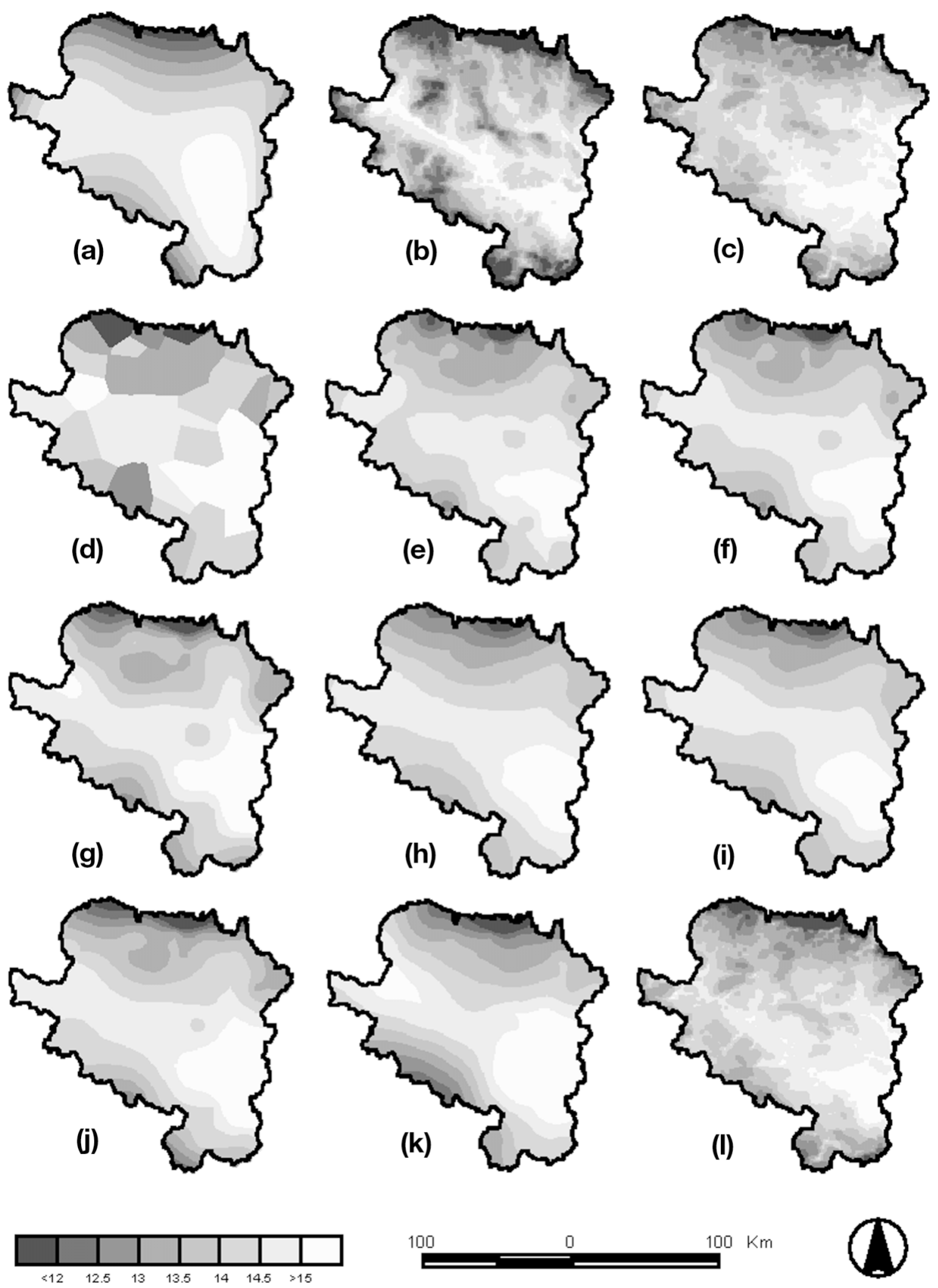

0

$100 \mathrm{Km}$

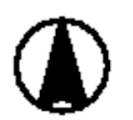

Fig. 6. Results of interpolation methods for annual mean temperature $\left({ }^{\circ} \mathrm{C}\right)$. (a) Trend surface (fourth order); (b) Smart interpolation (inverse distance, $r=2$ ); (c) regression model; (d) Thiessen polygons; (e) inverse distance weighting $(r=2)$; (f) splines with tension; (g) smoothing splines; (h) ordinary kriging; (i) block kriging; (j) universal kriging with quadratic drift; (k) co-kriging; (l) regression model + residuals (inverse distance, $r=2$ ) 
drift (Fig. 6j) shows an area of low temperatures in the south that does not appear on the maps obtained with ordinary kriging (Fig. 6h) and block kriging (Fig. 6i). Co-kriging interpolation (Fig. 6k) enhances this band and extends it to the center of the valley.

The regression model corrected using residuals indicates few differences from the original model. We should only note that there are fewer areas with mean temperature above $15^{\circ} \mathrm{C}$ in the east than in the original model, while in the west higher temperatures are predicted.

Fig. 7 shows the differences between the observed annual temperatures in the test stations and the predictions obtained with the different methods. In general, the differences between real and predicted values are higher than the results shown in the precipitation analysis, and the coefficients of determination are lower than those for the precipitation maps. The values predicted by the fourth-order trend surface are significantly different $\left(r^{2}=0.68\right)$ from the temperatures recorded at the test stations. In the case of the Smart interpolation, the coefficient is even lower $\left(\mathrm{r}^{2}=\right.$ $0.55)$, while the highest coefficients are found for the regression model $\left(\mathrm{r}^{2}=0.75\right)$ and in the same model corrected by residual interpolation $\left(\mathrm{r}^{2}=0.74\right)$. The Thiessen polygon method has $\mathrm{r}^{2}=0.63$. Curiously, the observed and predicted values in this map, whose spatial distribution is very far from the real temperature distribution, are much closer than on those in other, more realistic maps, such as the Smart interpolation, the universal kriging or the co-kriging maps. Finally, kriging methods show low coefficients of determination in relation to the precipitation results. In the temperature analysis, the coefficients oscillate from $\mathrm{r}^{2}=$ 0.39 for the co-kriging map to $\mathrm{r}^{2}=0.63$ for the block kriging model.

For the temperature analysis, the accuracy measurements are shown in Table 7. All measurements indicate less coincidence between real and predicted values than for precipitation and show the great difficulty of mapping annual mean temperatures in the middle Ebro Valley. The models differ from each other in important ways. The coefficients of determination, the initial adjustment measurement between observed and predicted data, show that the higher values correspond to the regression model $\left(r^{2}=0.75\right)$ and to the same map corrected by residual interpolation using inverse distance weighting $\left(\mathrm{r}^{2}=0.74\right)$. The lowest coefficients of determination are shown in the third-order trend surface $\left(\mathrm{r}^{2}=0.48\right)$, co-kriging $\left(\mathrm{r}^{2}=0.39\right)$ and Smart interpolation, using inverse distance weighting $\left(\mathrm{r}^{2}=0.55\right)$ and splines $\left(\mathrm{r}^{2}=0.52\right)$ to map the average annual air temperature at sea level.

Among the global methods, the regression model is the closest to the climatic data observed at the test sta- tions. Even though $D$ is equal in fourth- and fifth-order trend surface models and in the regression model $(D=$ $0.87), \mathrm{EF}$ is higher in the regression model $(\mathrm{EF}=0.56)$, and the error statistics (MAE and RMSE) are lower. In relation to local methods, the inverse distance weighting $(r=2)$ is the most accurate, in that it is closest to the real data observed at the test stations. Although $D$ is higher using $r=3(D=0.81)$, the use of $r=2$ indicates lower values of RMSE and MAE and higher values of $\mathrm{r}^{2}$ and EF. The models obtained from spline methods show higher errors than the maps created by inverse distance weighting and, curiously, those created by the Thiessen polygon method, which in spite of its chaotic shape (Fig. 6) shows better accuracy measurements than other methods. The different kriging methods show similar results, although co-kriging produces the worst map of all the models performed. As in the precipitation analysis, the correction of regression models using residuals does not improve the original model. The Smart interpolation method gives a bad result, in that the RMSE values are higher than $0.7^{\circ} \mathrm{C}$ and the EF values are less than 0.35 . Therefore, Smart interpolation does not seem an adequate method to perform temperature map models in the middle Ebro Valley, although temperatures correlate significantly with elevation $(\mathrm{r}=-0.74)$ in this area.

\section{DISCUSSION AND CONCLUSIONS}

The availability of high-quality climatic maps is a key issue for agricultural and hydrological management in many regions of the world, especially in Mediterranean areas, where water is a primary resource. The creation of digital grid maps makes it possible to obtain climatic information at any point, whether there is a weather station there or not. In this study, we show that the creation of climatic maps must start with an application of different mapping techniques and then a comparison of the results to determine the validity of the final models. This process is very important, because subsequent agricultural or hydrological decisions may differ depending on the information available.

The best method varies as a function of the area and the spatial scale desired for mapping. Areas of great topographic complexity and regions with contrasting atmospheric or oceanic influences present more problems than flatter areas or regions with constant atmospheric patterns. Nevertheless, regardless of geographic characteristics, we must start from a comparison of interpolation techniques to select the best possible model, because even in areas in which geographic differences and spatial climatic diversity are significant (e.g. the middle Ebro Valley), the differences between the models can be marked. Moreover, the 

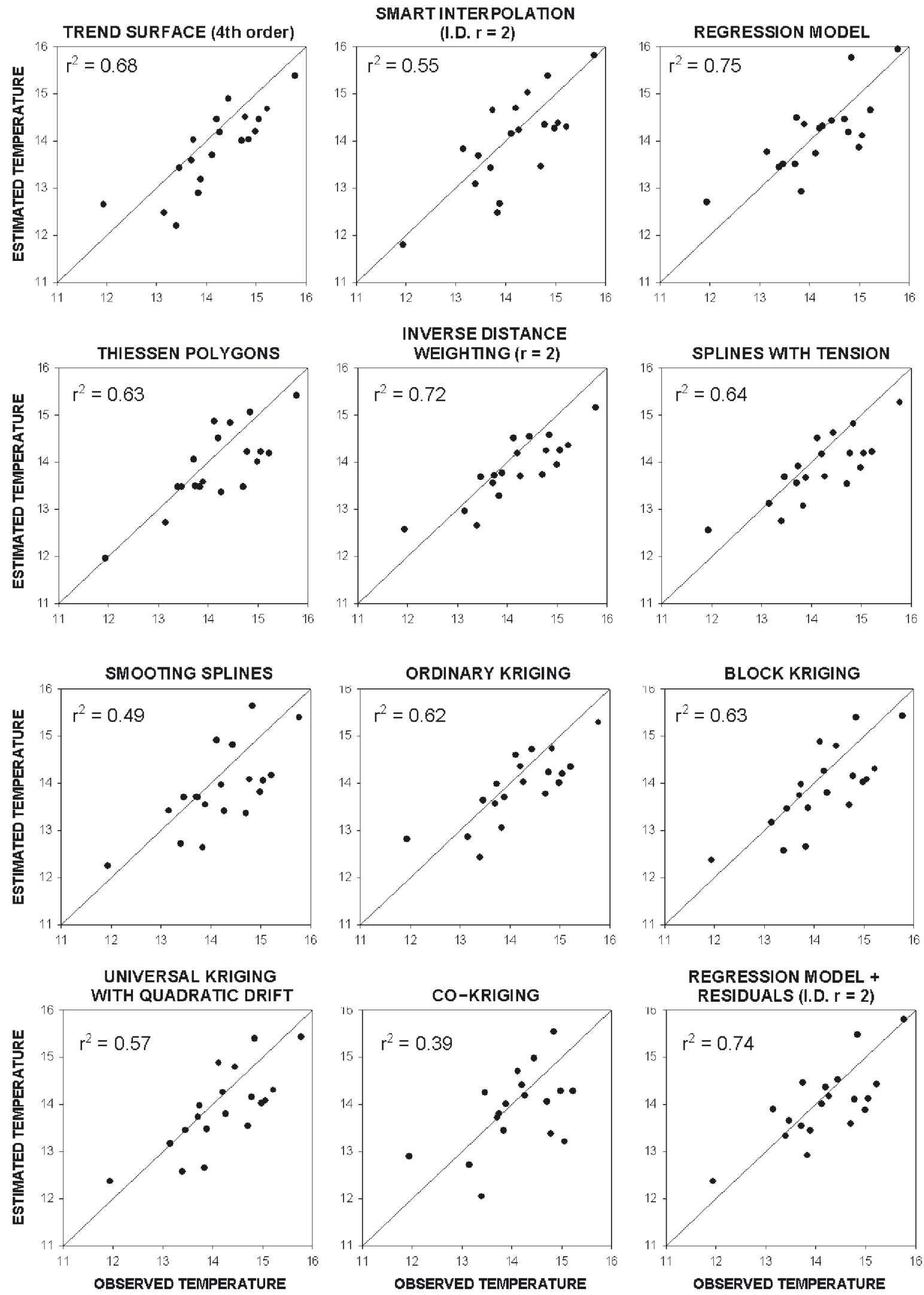

Fig. 7. Differences between observed and predicted values for temperature $\left({ }^{\circ} \mathrm{C}\right)$ in different models 
Table 7. Accuracy measurements for temperature models. Mean, MBE, RMSE and MAE are expressed in ${ }^{\circ} \mathrm{C}$

\begin{tabular}{|c|c|c|c|c|c|c|c|c|c|}
\hline Model & Mean & $\mathrm{r}^{2}$ & Slope & Intercept & RMSE & $\mathrm{MBE}$ & MAE & EF & $D$ \\
\hline Trend surface (first order) & 13.84 & 0.64 & 0.44 & 7.62 & 0.65 & -0.34 & 0.50 & 0.42 & 0.77 \\
\hline Trend surface (second order) & 14.03 & 0.55 & 0.72 & 3.82 & 0.63 & -0.16 & 0.55 & 0.46 & 0.84 \\
\hline Trend surface (third order) & 13.93 & 0.48 & 0.77 & 3.07 & 0.76 & -0.25 & 0.60 & 0.22 & 0.81 \\
\hline Trend surface (fourth order) & 13.84 & 0.68 & 0.81 & 2.40 & 0.61 & -0.35 & 0.53 & 0.50 & 0.87 \\
\hline Trend surface (fifth order) & 13.92 & 0.65 & 0.86 & 1.79 & 0.62 & -0.26 & 0.51 & 0.49 & 0.87 \\
\hline $\begin{array}{l}\text { Smart interpolation } \\
\text { (inverse distance, } r=2 \text { ) }\end{array}$ & 13.98 & 0.55 & 0.85 & 1.99 & 0.70 & -0.20 & 0.57 & 0.33 & 0.84 \\
\hline $\begin{array}{l}\text { Smart interpolation } \\
\text { (splines with tension, } \varphi=400 \text { ) }\end{array}$ & 14.01 & 0.52 & 0.82 & 2.38 & 0.71 & -0.18 & 0.58 & 0.31 & 0.83 \\
\hline Regression model & 14.13 & 0.75 & 0.82 & 2.60 & 0.58 & -0.06 & 0.46 & 0.56 & 0.87 \\
\hline Thiessen polygons & 13.91 & 0.63 & 0.75 & 3.27 & 0.61 & -0.27 & 0.49 & 0.50 & 0.86 \\
\hline Inverse distance weighting $(r=1)$ & 13.89 & 0.69 & 0.57 & 5.84 & 0.57 & -0.29 & 0.46 & 0.55 & 0.84 \\
\hline Inverse distance weighting $(r=2)$ & 13.86 & 0.72 & 0.65 & 4.66 & 0.56 & -0.32 & 0.46 & 0.57 & 0.86 \\
\hline Inverse distance weighting $(r=3)$ & 13.84 & 0.71 & 0.71 & 3.81 & 0.58 & -0.34 & 0.47 & 0.55 & 0.87 \\
\hline Splines with tension $(\varphi=400)$ & 13.86 & 0.64 & 0.63 & 4.90 & 0.61 & -0.32 & 0.49 & 0.50 & 0.84 \\
\hline Splines with tension $(\varphi=5000)$ & 13.91 & 0.66 & 0.59 & 5.57 & 0.58 & -0.28 & 0.47 & 0.55 & 0.85 \\
\hline Smoothing splines $[T(x, y)=0]$ & 13.85 & 0.49 & 0.70 & 3.90 & 0.74 & -0.33 & 0.62 & 0.26 & 0.81 \\
\hline Smoothing splines $[T(x, y)=400]$ & 13.90 & 0.58 & 0.68 & 4.28 & 0.64 & -0.29 & 0.54 & 0.45 & 0.84 \\
\hline Simple kriging & 13.89 & 0.62 & 0.65 & 4.71 & 0.61 & -0.30 & 0.52 & 0.50 & 0.84 \\
\hline Ordinary kriging & 13.91 & 0.62 & 0.66 & 4.55 & 0.60 & -0.28 & 0.50 & 0.51 & 0.85 \\
\hline Block kriging & 13.88 & 0.63 & 0.65 & 4.71 & 0.61 & -0.31 & 0.52 & 0.50 & 0.84 \\
\hline Ordinary kriging with anisotropy & 13.79 & 0.71 & 0.64 & 4.65 & 0.61 & -0.39 & 0.51 & 0.49 & 0.84 \\
\hline Universal kriging with linear drift & 13.84 & 0.61 & 0.71 & 3.71 & 0.65 & -0.34 & 0.51 & 0.43 & 0.84 \\
\hline Universal kriging with quadratic drift & 13.89 & 0.57 & 0.74 & 3.39 & 0.66 & -0.29 & 0.54 & 0.40 & 0.84 \\
\hline Co-kriging & 14.00 & 0.39 & 0.68 & 4.33 & 0.80 & -0.19 & 0.63 & 0.13 & 0.78 \\
\hline $\begin{array}{l}\text { Regression model }+ \text { residuals } \\
\text { (inverse distance, } r=2 \text { ) }\end{array}$ & 14.00 & 0.74 & 0.82 & 2.65 & 0.62 & -0.18 & 0.50 & 0.48 & 0.85 \\
\hline $\begin{array}{l}\text { Regression model }+ \text { residuals } \\
\text { (splines with tension, } \varphi=400 \text { ) }\end{array}$ & 13.98 & 0.70 & 0.76 & 3.52 & 0.67 & -0.20 & 0.54 & 0.44 & 0.82 \\
\hline
\end{tabular}

best mapping method may change as a function of the climatic variable mapped, because the factors that determine spatial distribution may differ for different variables. In this paper, we show that in the middle Ebro Valley the results of the same interpolation methods differ considerably according to whether temperature or precipitation is being mapped.

Topographic, geographic and atmospheric factors, which determine the spatial distribution of the climatic variables, condition the difficulty of map creation. For example, mapping annual mean temperatures is easier than minimum temperatures, because to predict the latter, situations such as thermal inversions would have to be included (Daly et al. 2002). This is especially true in lower-elevation areas such as the center of the middle Ebro Valley, where these situations are very common. We obtained better predictions using precipitation mapping than using temperature mapping, unlike Goodale et al. (1998), Agnew \& Palutikof (2000) or Ninyerola et al. (2000). Their regression models of temperatures and precipitation in the Mediterranean Basin, Catalonia (Spain) and Ireland, respectively, showed that precipitation mapping gave more problems than temperature mapping. In the middle Ebro Valley, the relationships between geographic and topographic variables and the spatial distribution of temperature can be more complex than those for precipitation. The main topographic factor, elevation, has less influence on the temperature distribution in the middle Ebro Valley than in other areas. Here, the coefficient of determination $\left(\mathrm{r}^{2}\right)$ between temperature and elevation is only 0.55 , less than that for precipitation $\left(\mathrm{r}^{2}=0.64\right)$. The poor results shown by Smart interpolation and co-kriging, the 2 methods that consider elevation as the only auxiliary variable in temperature interpolation, underline how elevation is not the only variable that conditions the spatial distribution of temperature in the study area.

The selection of the temporal scale can have important effects on interpolation results. As climate varies richly, on a seasonal, monthly or even daily temporal scale, the validity of an interpolation technique could change according to the time frame. Because of this, the selection of the best method may depend on the temporal scale used. For example, Agnew \& Palutikof (2000) show that spatial variance explained by different regression models, in order to obtain temperature and precipitation seasonal maps in the Mediterranean Basin, varies significantly between one station and another. Ninyerola et al. (2000) also show that the validity 
of regression models and the explanatory variables changes substantially according to the month of the year and the climatic variable modeled. Seasonal changes in direction and intensity of the wind flows may complicate spatial modeling of temperatures and precipitation: leeward slopes in winter can become windward slopes in summer and vice versa. The problem is greater when creating daily maps, due to very high daily spatial and temporal climatic variability (e.g. convective precipitation, local thermal inversions and different directions of wind flows on consecutive days).

As the same analysis can give different results in different areas, prior tests need to be established to determine the most adequate method in each case. In mountainous areas and in regions with complex atmospheric influences, the global trend surfaces, the local interpolators and geostatistics which do not use external variables, do not show the spatial richness of climate at local scales and do have higher errors in prediction (Hevesi et al. 1992, Ishida \& Kawashima 1993, Martínez-Cob 1996, Pardo-Igúzquiza 1998). This is true for the middle Ebro Valley too. The use of the different topographic and geographic factors that determine the spatial distribution of climatic variables makes it possible to map more local climatic features. The creation of models establishing empirical relationships between variables enables us to make maps that reflect the real spatial richness of the climatic data, whereas the other methods smooth the final results much more. Nowadays, multiple regression method is very common in the mapping of climatic variables, because it adapts to almost any space and usually generates adequate maps (Vogt et al. 1997, Goodale et al. 1998, Ninyerola et al. 2000).

In the middle Ebro Valley, we showed that the inclusion of several variables in temperature and precipitation mapping leads to maps that reflect reality more closely; for example, elevation is insufficient in explaining the spatial distribution of climatic variables. Distance from water bodies can be a determining factor in the prediction of precipitation and temperature. Distances from the Mediterranean and Cantabrian Seas, included in temperature and precipitation regression models, gave excellent results in both cases. In local or geostatistical methods, the influence of sea distance was also noted, with higher temperatures near the Mediterranean and higher precipitation closer to the Cantabrian Sea. Nevertheless, the effects that relief and distance from water bodies exercise jointly on climatic distribution were only reflected well on the regression maps, which shows that the effects of relief differ as a function of geographical location and the influence of other variables. In addition, the influence of relief on the distribution of climatic variables in the study area was not spatially homogeneous.
Other factors modify more locally the values of climatic variables. For example, the aspect of the different areas to air-flow directions (e.g. steep, bulky features oriented normal to the average air flow generally cause steeper precipitation-elevation slopes than low, gently rising slopes parallel to the air flow). Brundsdon et al. (2001) indicated that the relationship between precipitation and elevation changes significantly according to wind direction. Konrad (1996) also showed variations in the spatial distribution of precipitation as a function of the dominant wind flows within the United States. In the middle Ebro Valley, the atmospheric patterns and the direction of the wind determine the spatial distribution of climatic variables. This is shown by the inclusion of related variables $\left(Z_{5} N, Z_{5} W, Z_{5} S\right.$ and $\left.Z_{25} S\right)$. The mountain ranges located in the northern area receive greater precipitation during the seasons, with intense westerlies and low pressures associated with polar fronts (winter), whereas the southeastern areas are affected by Mediterranean flows (more intense in fall). The same atmospheric factors condition precipitation distribution in the flattest areas, but there is great uncertainty about the type of dominant influence, because in some years Mediterranean patterns prevail, while in others NW flows are dominant (Creus 1983).

As far as statistical results are concerned, in the middle Ebro Valley the different precipitation models show few statistic differences, including the models that do not utilize auxiliary (topographic or geographic) information, such as several of the different kriging methods, give good results and are consistent with observed values. Nevertheless, on the basis of our knowledge of the climate in the region, we state that the regression model map shows high diversity at a local scale, which is closer to reality. This model shows, for example, higher precipitation in the marginal relief in the center of the valley than in surrounding areas, as well as local details in the precipitation in the mountainous relief of the northern and SE sectors. Moncayo mountain (west of the study area) is an 'island of high precipitation' in the valley, and it is only recognized in the regression model.

For temperature mapping, it has been shown that the distribution of annual means is highly conditioned by topographic factors, fundamentally elevation, but also by distance to seas and oceans, and by the presence of topographic shadows at different spatial scales. Using only elevation as the auxiliary information when mapping, as in Smart interpolation and co-kriging, leads to worse results than when other variables are included. Even though the accuracy measurements give small differences between the final regression model and the maps obtained from local interpolations, it is better to use the map obtained by applying the empirical 
regression model, because it provides a more accurate reflection of thermal diversity at a local scale. In addition, regression-based methods are not as conditioned by the location of the weather stations as local and geostatistical methods, which give better predictions in areas with low spatial density of available data.

Although the topography of the middle Ebro Valley is not very complex, geographic differences and spatial climatic diversity are significant (Vicente \& Cuadrat 2001). The annual temperature and precipitation maps developed here can be very useful for hydrological and agricultural management in the region (CIRCE 2001). These maps must be the first step in the creation of a more complete spatial climatic database, which includes the diversity offered by seasonal or monthly temporal scales, and of temporal map series (New et al. 2000, Brown \& Comrie 2002). The latter, which are very useful for planning, expand our understanding of spatial climatic complexity and its variation over time in the study area.

The main conclusion to be drawn from this paper is that, given the importance of making climatic maps that correspond closely to reality, different interpolation methods need to be tested before the most appropriate scheme for a given area and climatic variable is selected. The versatility of the geographic information systems and the inclusion of most major interpolation methods in common software packages make the process of producing and comparing climatic maps easier. Reliable calculations for agricultural and hydrological management, and the improvement of climatic models at local scales, can thus be obtained with increased efficiency.

Acknowledgements. This research was funded by the Ministerio de Ciencia y Tecnología through the projects CLI99-0981 and BSO2002-02743. We express our gratitude to the Meteorological Center in Zaragoza for the provided meteorological data, and we would like to thank to Drs. J. C. González-Hidalgo and A. C. Comrie and the 3 anonymous reviewers for their helpful comments. We also thank specially Mr. R. Rycroft for his linguistic revision.

\section{LITERATURE CITED}

Agnew MD, Palutikof JP (2000) GIS-based construction of base line climatologies for the Mediterranean using terrain variables. Clim Res 14:115-127

Alexandersson H, Moberg A (1997) Homogenization of Swedish temperature data. Part I. Homogeneity test for linear trends. Int J Climatol 17:25-34

Ascaso A, Casals M (1981) Periodos secos y sequías en la depresión central del Ebro. Geographicalia 11-12:55-71

Atkinson PM (1997) Geographical information science. Prog Phys Geogr 21:573-582

Austin RB, Cantero-Martínez C, Arrúe JL, Playán E, CanoMarcellán P (1998) Yield-rainfall relationships in cereal cropping systems in the Ebro river valley of Spain. Eur J Agron 8:239-248
Bacchi B, Kottegoda NT (1995) Identification and calibration of spatial correlation patterns of rainfall. J Hydrol 165: 311-348

Basist A, Bell GD, Meentemeyer V (1994) Statistical relationships between topography and precipitation patterns. J Clim 7:1305-1315

Bigg GR (1991) Kriging and intraregional rainfall variability in England. Int J Climatol 11:663-675

Blennow K, Persson P (1998) Modelling local-scale frost variations using mobile temperature measurements with a GIS. Agricult For Meteorol 89:59-71

Bonacina LCW (1945) Orographic rainfall and its place in the hydrology of the globe. Q J R Meteorol Soc 71:41-55

Borrough PA, McDonnell RA (1998) Principles of geographical information systems. Oxford University Press, Oxford

Brown DP, Comrie AC (2002) Spatial modeling of winter temperature and precipitation in Arizona and New Mexico, USA. Clim Res 22:115-128

Brundsdon C, McClatchey J, Unwin DJ (2001) Spatial variations in the average rainfall-altitude relationship in Great Britain: an approach using geographically weighted regression. Int J Climatol 21:455-466

CIRCE (Centro de Investigación de Recursos y Consumos Energéticos) (2001) Spanish hydrologic plan and sustainable water management: environmental aspects, water reuse and desalination. International Conference, Zaragoza, June 13-14, 2001. CIRCE, Zaragoza

Cressie N (1990) The origins of kriging. Math Geol 22: $239-253$

Creus J (1983) El clima del alto Aragón occidental. Serie Monografías 109, Instituto de estudios Pirenaicos, Jaca

Creus J (1996) Variaciones en la disponibilidad hídrica mensual en el valle del Ebro. In: Marzol MV, Dorta P, Valladares P (eds) Clima y agua: la gestión de un recurso climático. University of la Laguna, Tenerife, p 79-86

Creus J, Ferraz J (1995) Irregularidad pluviométrica y continentalidad térmica en el valle medio del Ebro. Lucas Mallada 7:147-164

Cuadrat JM (1999) El clima de Aragón. Caja de Ahorros de la Inmaculada, Zaragoza

Curran PJ, Atkinson PM (1998) Geostatistics and remote sensing. Prog Phys Geogr 22:61-78

Daly C, Neilson RP, Phillips DL (1994) A statistical-topographical model for mapping climatological precipitation over mountainous terrain. J Clim Appl Meteorol 33:140-158

Daly C, Gibson WP, Taylor GH, Johnson GL, Pasteris P (2002) A knowledge-based approach to the statistical mapping of climate. Clim Res 22:99-113

Dingman SL, Seely-Reynolds DM, Reynolds RC (1988) Application of kriging to estimating mean annual precipitation in a region of orographic influence. Water Resour Bull 24: 329-339

Easterling DR, Peterson T (1995) A new method for detecting undocumented discontinuities in climatological time series. Int J Climatol 15:369-377

Edwards KA (1972) Estimating areal rainfall by fitting surfaces to irregularly spaced data. In: Proc Int Symp Distribution of Precipitation in Mountainous Areas, Vol 2. World Meteorological Organisation, Geneva, p 565-587

Goodale CL, Aber JD, Ollinger SV (1998) Mapping monthly precipitation, temperature and solar radiation from Ireland with polynomial regression and a digital elevation model. Clim Res 10:35-49

Goovaerts P (1997) Geostatistics for natural resources evaluation. Oxford University Press, New York

Goovaerts P (1999) Using elevation to aid the geostatistical mapping of rainfall erosivity. Catena 34:227-242 
Goovaerts P (2000) Geostatistical approaches for incorporating elevation into the spatial interpolation of rainfall. J Hydrol 228:113-129

Greenwood DJ, Neteson JJ, Drayscott A (1985) Response of potatoes to $\mathrm{N}$ fertilizer: dynamic model. Plant Soil 85: 185-203

Hargy VT (1997) Objectively mapping accumulated temperature for Ireland. Int J Climatol 17:909-927

Hevesi JA, Flint AL, Istok JD (1992) Precipitation estimation in mountainous terrain using multivariate geostatistics. Part II. Isohyetal maps. J Clim 31:677-688

Hutchinson MF (1995) Interpolating mean rainfall using thin plate smoothing splines. Int J Geogr Inf Syst 9:385-403

Isaaks EH, Strivastava RM (1989) An introduction to applied geostatistics. Oxford University Press, Oxford

Ishida T, Kawashima S (1993) Use cokriging to estimate surface air temperature from elevation. Theor Appl Climatol 47:147-157

Karnieli A (1990) Application of kriging technique to areal precipitation mapping in Arizona. Geojournal 22: 391-398

Konrad CE II (1996) Relationships between precipitation event types and topography in the southern blue ridge mountains of the southeastern USA. Int J Climatol 16: $49-62$

Martínez-Cob A (1996) Multivariate geostatistical analysis of evapotranspiration and precipitation in mountainous terrain. J Hydrol 174:19-35

Maseli F, Conese C, Petkov L, Maracchi G (1996) Eco-climatic classification of Tuscany through NOAA-AVHRR data. Int J Remote Sensing 17:2369-2384

Maseli F, Petkov L, Maracchi G (1998) Extension of climate parameters over the land surface by the use of NOAAAVHRR and ancillary data. Photogram Eng Remote Sensing 64:199-206

McAneney KJ, Arrúe JL (1993) A wheat-fallow rotation in north-eastern Spain: water balance-yield considerations. Agronomie 13:481-490

Mitasova H, Mitas L, Brown WM, Gerdes DP, Kosinovsky I, Baker T (1995) Modelling spatially and temporally distributed phenomena: new methods and tools for GRASS GIS. Int J Geogr Inf Syst 9:433-446

New M, Hulme M, Jones P (2000) Representing twentiethcentury space-time climate variability. Part II. Development of 1901 monthly grids of terrestrial surface climate. J Clim 13:2217-2238

Ninyerola M, Pons X, Roure JM (2000) A methodological approach of climatological modelling of air temperature and precipitation through GIS techniques. Int J Climatol 20:1823-1841

Pardo-Igúzquiza E (1998) Comparison of geostatistical methods for estimating the areal average climatological rainfall mean using data of precipitation and topography. Int $\mathrm{J}$ Climatol 18:1031-1047

Pebesma EJ, Wesseling CG (1998) GSTAT, a program for geostatistical modelling, prediction and simulation. Comput Geosci 24:17-31

Pedrocchi C (1998) Ecología de los Monegros. Instituto de Estudios Altoaragoneses, Huesca

Pellicer F, Echeverría MT (1990) Formas de relieve del centro de la Depresión del Ebro. Institución Fernando el Católico, Zaragoza

Editorial responsibility: Andrew Comrie,

Tucson, Arizona, USA
Peterson TC, Easterling DR (1994) Creation of homogeneous composite climatological reference series. Int J Climatol 14:671-679

Peterson TC, Vose R, Schmoyer R, Razuvaëv V (1998) Global historical climatology network (GHCN) quality control of monthly temperature data. Int J Climatol 18:1169-1179

Phillips DL, Dolph J, Marks D (1992) A comparison of geostatistical procedures for spatial analysis of precipitation in montainous terrain. Agricult For Meteorol 58:119-141

Pons X (1997) Estimación de la radiación solar a partir de modelos digitales de elevaciones: propuesta metodológica. In: Juaristi J, Moro I (eds) Modelos y sistemas de informaciónen geográfica. Asociación de Geógrafos Españoles, Vitoria, p 87-97

Pons X (1998) Manual of Miramon: geographic information system and remote sensing software. Centre de Recerca Ecològica i Aplicacions Forestals (CREAF), Bellaterra (available at http://www.creaf.uab.es/miramon)

Prudhomme C, Reed DW (1998) Relationships between extreme daily precipitation and topography in a mountainous region: a case study in Scotland. Int J Climatol 18: $1439-1453$

Prudhomme C, Reed DW (1999) Mapping extreme rainfall in a mountainous region using geostatistical techniques: a case study in Scotland. Int J Climatol 19:1337-1356

Rhoades DA, Salinger MJ (1993) Adjustment of temperature and rainfall records for site changes. Int J Climatol 13: 899-913

Salas J, Chuvieco E (1993) Modelización de variables microclimáticas a partir de un sistema de información geográfica. In: $2^{\circ}$ Congreso de la Asociación Española de Sistemas de Información Geográfica. Asociación de Geógrafos Españoles, Madrid, p 423-446

Suárez F, Sainz H, Santos T, Bernáldez FG (1992) Las estepas ibéricas. Ministerio de Obras públicas y Transportes, Madrid

Tabony RC (1985) Relations between minimum temperature and topography in Great Britain. J Climatol 5:503-520

Thiessen AH (1911) Precipitation averages for large areas. Mon Weather Rev 39:1082-1084

Vicente SM, Cuadrat JM (2001) Desarrollo de una metodología para la evaluación de la variabilidad espacial en la intensidad de los periodos secos: aplicación en el valle medio del río Ebro. In: Pérez-Cueva AJ, López E, Tamayo J (eds) El tiempo del clima. Asociación Española de Climatología, Valencia. p 255-267

Vogt JV, Viau AA, Paquet F (1997) Mapping regional air temperature fields using satellite derived surface skin temperatures. Int J Climatol 17:1559-1579

Willmott CJ (1981) On the validation of models. Phys Geogr 2: $184-194$

Willmott CJ (1982) Some comments on the evaluation of model performance. Bull Am Meteorol Soc 63:1309-1313

Willmott CJ, Matsuura K (1995) Smart interpolation of annually averaged air temperature in the United States. J Appl Meteorol 34:2577-2586

Willmott CJ, Robeson SM (1995) Climatologically aided interpolation (CAI) of terrestrial air temperature. Int J Climatol 15:221-229

Willmott CJ, Rowe CM, Philpot WD (1985) Small-scale climate maps: a sensitivity analysis of some common assumptions associated with grid-point interpolation and contouring. Am Cartographer 12:5-16

Submitted: July 15, 2002; Accepted: April 14, 2003

Proofs received from author(s): June 27, 2003 